\title{
Spectrum of Tuberculosis in Human Body - A Radiologic Review
}

\author{
Ravishankar Pillenahalli Maheshwarappa ${ }^{1}$, Amit Gupta $^{2}$, Juhi Bansal ${ }^{3}$, \\ Mangi Lal Meena ${ }^{4}$ \\ ${ }^{1}$ (Department of Radiodiagnosis, Adichunchanagiri Institute of Medical Sciences, Bellur, Karnataka, India) \\ ${ }^{2}$ (Department of Radiodiagnosis, Adesh Institute of Medical Sciences \& Research, Bathinda, India) \\ ${ }_{3,4}$ (Department of Radiodiagnosis , Ravindra Nath Tagore Medical College, Udaipur, India)
}

\begin{abstract}
Tuberculosis (TB) is a multisystem disease which can affect virtually any part of the body and is associated with high mortality and morbidity if not adequately treated. With the emergence of HIV and multidrug resistant strains, $T B$ is no longer a health problem of developing countries alone but a global health concern. TB demonstrates a variety of clinical and radiologic findings that can mimic numerous other disease entities. Hence it is important for radiologists to be familiar with the various imaging manifestations of TB so as to make an accurate diagnosis and aid in initiating timely treatment. This review article illustrates the imaging spectrum of tuberculosis with reference to various body systems.
\end{abstract}

Keywords: Tuberculosis, spectrum, human body, multisystem disease

\section{Introduction:}

Tuberculosis (TB) is an infectious disease caused by Mycobacterium tuberculosis and at present is a considerable health problem in the world with most of the cases concentrated in third world countries. This trend has been attributed to the low standard of living and scarcity of health resources in these countries $[1,2]$. Global emergence of acquired immunodeficiency syndrome (AIDS) has further complicated the scenario and has dragged economically developed countries into the equation. Although thorax is the most commonly involved site, tuberculosis can affect any system in the body including skeleton, genitourinary tract and central nervous system [3]. In this paper, we describe the spectrum of imaging findings of TB based on cases encountered in our clinical practice.

\section{Pulmonary Tuberculosis :}

Pulmonary TB can be broadly divided into primary and postprimary TB based on absence or presence of prior infection and acquired specific immunity [4]. However the radiological appearances of these entities may show a considerable overlap.

\section{Primary Tuberculosis :}

Primary TB is most commonly seen in children however increasing prevalence has been noted in adult population .It may manifest as lymphadenopathy, parenchymal disease, pleural effusion, miliary disease or atelectasis $[3,5]$.

Lymphadenopathy is classically unilateral and right sided involving the hilar and paratracheal regions. In active disease, the lymph nodes are generally more than $2 \mathrm{cms}$ in diameter, on CT reveal low attenuation center representing caseous necrosis and peripheral enhancement representing rim of inflammatory tissue [6]. [Fig 1]

Parenchymal disease may present as homogenous areas of consolidation or patchy, linear, nodular or mass like lesions. Affection is usually unilateral and shows no predilection for any particular lung zone $[4,7]$. [Fig 2a, 2b]

Pleural effusion is typically unilateral and usually occurs on the same side of the infection. It many cases it may be the only pulmonary abnormality in the absence of any parenchymal disease [8]. [Fig 3]. Unlike postprimary TB, complications like empyema, bronchopleural fistula and bone erosion are quite rare [6].

In miliary tuberculosis radiographs are normal in the initial stages and hyperinflation may be the only finding. Characteristic appearance on plain radiography and CT is numerous, 1-3 mm, non calcified nodules diffusely scattered throughout the lung.[Fig 4a, 4b] [6,9].

\section{Postprimary Tuberculosis:}

It is primarily seen in adolescents and adults. Unlike primary tuberculosis, postprimary TB is a progressive condition and is rarely associated with hilar or mediastinal lymphadenopathy[6,8]. It usually presents as parenchymal, airway and pleural involvement. 
The earliest radiological finding is focal or patchy areas of consolidation preferably involving apical or posterior segments of upper lobes and the superior segments of the lower lobes[4].

Cavitation is hallmark of postprimary TB and indicates active disease. Cavities usually occur in areas of consolidation and show thick irregular walls with or without air fluid levels. From here the disease may either progress or heal with fibrosis resulting in volume loss and tractional bronchiectasis [4,5,10].[Fig 5a,5b,5c] Occasionally, the cavitatory disease may be complicated with intracavitatory fungal masses which are freely mobile and give the characteristic air crescent sign on imaging. [Fig 6a,6b]

Bronchogenic spread occurs when area of caseous necrosis communicates with the bronchial tree. CT reveals 2-4-mm centrilobular nodules and branching linear opacities originating from a single stalk(tree in bud pattern) [Fig 7] This pattern is highly suggestive but not pathognomic of active tuberculosis.[11,12]

Airway involvement is in form of bronchial stenosis from extrinsic compression by the adjacent enlarged lymph nodes resulting in either obstructive atelectasis or overinflation. This has to be differentiated from more sinister pathologies like endobronchial masses which have similar imaging appearances[6,13]. Pleural effusions are usually small in post primary tuberculosis and may be associated with complications like empyema [Fig 8a, 8b] and bronchopleural fistula formation[3].[Fig 9]

\section{Abdominal Tuberculosis}

Abdomen is the most common site for extrapulmonary TB. Recently abdominal tuberculosis has shown increasing incidence not only in developing but also in developed countries. This has been largely attributed to the increase in AIDS patients [14].

\section{Lymphadenopathy:}

In tubercular lymphadenopathy generally there is simultaneous affection of multiple lymphnode groups. However, mesenteric and peripancreatic are the commonest involved groups, reflecting the lymphatic drainage from small bowel, ileocaecum, right side of colon, liver and spleen $[15,16]$.

On Ultrasonography (US), tubercular lymph nodes are usually hypoechoic with anechoic centres indicating caseous necrosis. Calcification may be seen in the healing stage of disease . CT scan characteristically shows enlarged matted or discrete lymph nodes with hypodense centres and peripherally enhancing rims on post contrast scans. However, this pattern is not pathognomic of tuberculosis as it may be seen in various malignant (metastases from carcinoma ovaries /gastrointestinal tract, and lymphoma, especially post treatment) and benign conditions (Crohn's disease, Sarcoidosis, Whipple's disease and Castleman's disease) [16,17].

\section{Tuberculous peritonitis:}

It is frequently seen in association with other forms of abdominal TB like lymphnode and gastrointestinal TB. It is broadly classified into three types based on the amount of ascitic fluid.

Wet type is the most common and is associated with large amounts of free or loculated ascitic fluid which shows higher attenuation (20-45 HU) than water on CT. [Fig 10]

Fibrotic-fixed type is characterised by cake like masses of omentum and mesentery with matted bowel loops, and may show loculated ascites. Mesenteric involvement can range from linear stranding to stellate appearance created by radiating thickened mesenteric bands [Fig 11].

Dry-plastic type is characterised by dense fibrous adhesions and uniform peritoneal thickening. Nodular implants with irregular peritoneal thickening are extremely rare and favour disseminated peritoneal malignancy $[15,16,18]$.

The imaging findings of peritoneal TB are non specific and conditions like peritoneal carcinomatosis, mesothelioma, nontuberculous peritonitis and lymphoma should be considered as possible differentials [19].

\section{Gastrointestinal Tuberculosis}

Gastrointestinal(GI) tuberculosis involves ileocaecal region in most of the cases (80-90\%). This has been linked to abundance of lymphoid tissue and relative stasis of bowel contents in this region[19,20].

GI tuberculosis assumes one of the three forms, namely ulcerative, hypertrophic or ulcerohypertrophic. Ulcerative type is the most common form of the three. In TB, the ulcers are typically linear or stellate and follow the orientation of lymphoid follicles, therefore appear longitudinal in terminal ileum and transverse in colon.

Barium studies are commonly performed to pick up the mucosal lesions and the ulcers. As the progresses there would be narrowing of the terminal ileum with gaping of ileocaecal valve [19,20].

CT may show circumferential mural thickening of caecum and terminal ileum along with adjacent mesenteric lymphadenopathy [Fig 12a,12b]. In advanced cases, asymmetric thickening of ileocaecal valve and medial caecal wall, large lymphnode mass with engulfment of the terminal ileum can also be seen. Secondary involvement of the appendix is not uncommon. 
Differential diagnosis of ileocaecal TB includes amoebiasis, caecal carcinoma, Crohn's disease and lymphoma[15,21,22].

Other less frequent sites involved are esophagus (associated with AIDS), stomach (typically involve antrum and distal body), duodenum (predilection for third and fourth parts) $[19,20]$.

\section{Hepatosplenic Tuberculosis :}

Imaging is non specific and quite variable in hepatosplenic $\mathrm{TB}$, hence most of the times histopathological correlation is necessary. Hepatosplenic TB has two main types, micronodular (miliary) form and macronodular form[19,20]. [Fig 13]

The miliary form manifests as hepatoslenomegaly. US may depict diffusely increased echogenicity (bright liver and spleen pattern).CT may reveal tiny $(0.5-2 \mathrm{~mm})$ low attenuation foci.

The macronodular form is seen as single or multiple 1-3 cm sized nodular lesion in hepatic and splenic parenchyma with lesions appearing hypoechoic on US, and rarely hyperechoic. On CT, these lesions may or may not demonstrate peripheral rim enhancement [Fig 13, Fig 14]. Calcification may be seen in later stages of the disease. In immunocompromised patients, a tubercular abscess can also be noted.

The differential diagnosis for miliary for miliary form includes metastases, fungal infections, sarcoidosis, and lymphoma. The macronodular form can be confused with metastases, abscess, and primary malignancy[15,19,20,23,24]

\section{CNS Tuberculosis}

CNS infection involves the brain, meninges, and occasionally, the spinal cord [Table 1]. Although CNS involvement by tuberculosis is seen in all age groups, there is a predilection for younger patients, with 60 $70 \%$ of cases occurring in patients younger than 20 years of age [25].

Table 1 : Classification of CNS tuberculosis

\begin{tabular}{|l|l|}
\hline Intracranial & Spinal \\
\hline Tuberculous meningitis (TBM) & Pott's spine and Pott's paraplegia \\
\hline Tuberculous encephalopathy & Non-osseous spinal tuberculoma \\
\hline Tuberculous vasculopathy & Spinal meningitis \\
\hline CNS tuberculoma (single or multiple) & \\
\hline Tuberculous Brain Abscess & \\
\hline
\end{tabular}

\section{Tubercular meningitis}

The most common finding in cranial tuberculous meningitis (CTBM) on CT scan is obliteration of the basal cisterns by isodense or mildly hyperdense exudates. [Fig 15]. MR post-gado T1-weighted images show diffuse meningeal enhancement, mainly at the basal cisterns. Meningeal enhancement has been found in up to $90 \%$ of cases and is the most sensitive feature of tubercular meningitis. Parenchymal involvement is another complication of CTBM, manifesting as TB cerebritis and granuloma formation [26] [Fig 16]. The presence of basal exudates, infarcts and hydrocephalus is considered the diagnostic triad of tubercular meningitis [27].

\section{Tubercular encephalopathy}

The pathological basis of tuberculous encephalopathy was an allergic delayed type IV hypersensitivity reaction due to cell mediated immunity to tuberculin protein. A distinctive feature of this entity is its occurrence in a younger child or infant with pulmonary tuberculosis. The brain examination reveals severe diffuse brain oedema and pallor, especially of the white matter [28]

\section{Tubercular vasculopathy}

Vasculitis may be caused by direct invasion of the vessel by mycobacteria, or from extension of adjacent arachnoiditis. These may lead to spasm or thrombosis of the vessels, with resulting infarction, most frequently seen at the basal ganglia and internal capsule. Exudative meningitis may result in necrotising panarteritis, with secondary thrombosis and occlusion of small- and medium-sized vessels at the base of the brain, particularly the lenticulostriate and thalamoperforating arteries resulting in infarcts [29].

\section{Intracranial tuberculomas}

Tuberculomas are usually multiple and occur in the frontal and parietal lobes. Children's have a predominance of infratentorial lesions. At CT scan, tuberculomas manifest as low or high attenuation rounded or lobulated masses that commonly demonstrate ring enhancement on contrast enhanced images. These lesions are often associated with moderate to marked edema, but calcification is uncommon [30]. 
Tuberculomas consisting of non caseating granulomas are usually hypointense relative to the brain on T1-weighted images and hyperintense on T2-weighted images which shows homogeneous enhancement after gadolinium administration. Caseating granulomatous lesions with a solid center appear relatively hypointense or isointense on T1-weighted images and iso- to hypointense on T2-weighted images associated with surrounding edema. The lesion has a hypointense rim on T2 weighted images. Caseating lesions demonstrate rim enhancement at contrast-enhanced T1-weighted MR imaging [31][Fig 17a and 17b].

Intraventricular tuberculomas are also rarely reported, and may be associated with hydrocephalus, meningitis and ependymitis. Miliary CNS tuberculomas occur when there is diffuse infiltration of the brain by small granulomas that are less than $5 \mathrm{~mm}$ [32]. The differential diagnosis for parenchymal tuberculomas includes other granulomatous infections (eg, cysticercosis) and fungal lesions as well as primary or metastatic neoplasms [31].

\section{Tubercular Abscess}

Tubercular abscesses may be solitary or multiple and are more common in the elderly or in immunecompromised patients [32]. On imaging studies, abscesses are commonly found in the supratentorial compartment indistinguishable from a caseating tuberculoma, a pyogenic abscess or a caseating tuberculoma with liquefaction. Usually a tubercular abscess shows a uniformly thin and enhancing smooth walls. It is usually larger than $3 \mathrm{~cm}$ in diameter and commonly has a multilocular appearance[33] [Fig 18a, 18b].

\section{Spinal tuberculous meningitis}

The unenhanced MR images of spinal tuberculous meningitis (STBM) may appear unremarkable, or may show CSF loculation and obliteration of the spinal subarachnoid space with loss of outline of the spinal cord in the cervico-thoracic spine, and thickening and clumping of the nerve roots in the lumbar spine. Gadolinium-enhanced MR images show linear enhancement of the surface of the spinal cord and nerve roots, or plaque-like enhancement of the dura-arachnoid mater complex which obliterates the subarachnoid space. The spinal cord may be involved with parenchymal TB myelitis and tuberculoma formation, or as complications of arachnoiditis (e.g. infarction or syrinomyelia)[34] [Fig 19]

\section{Musculoskeletal tuberculosis}

The most common presentations are tuberculous spondylitis, arthritis, osteomyelitis, and soft tissue involvement. There are certain imaging features that help to differentiate tuberculosis from other bone and joint disorders with a similar presentation [35].

Conventional radiography is the mainstay in the diagnosis of tuberculous arthritis and osteomyelitis. $\mathrm{CT}$ is superior in the demonstration of calcifications, which are found in chronic tuberculous abscesses and for bone marrow and soft tissue abnormalities MR imaging is useful [35]. Aspiration or biopsy can lead to earlier recognition of musculoskeletal tuberculosis before the onset of debilitating disease. Surgery plays an important role in establishing a diagnosis and in treating complications of the musculoskeletal manifestations of tuberculosis [36].

\section{Osteomyelitis :}

The patient presents with localized pain and soft tissue swelling of few days to months duration, and may be accompanied by low grade fevers, weight loss, and malaise. Regional lymphadenopathy is common, and sinuses may be observed. Tuberculous dactylitis involves the short tubular bones of the hands and feet in children. At radiography, these lesions demonstrate soft-tissue swelling and periostitis. These findings are followed by gradual bone destruction and sequestrum formation. Expansion of the bone with cystic changes is known as spina ventosa [31].[Fig 20]

Tuberculous osteomyelitis mimics a variety of conditions on plain radiographs, and the most common finding is a solitary cystic lesion with a sclerotic rim. Lesions may cross the physis. The differential diagnosis includes neoplasm, Brodie's abscess, chronic osteomyelitis, and other granulomatous lesions, biopsy is required to establish the diagnosis. [37]

\section{Arthritis :}

The most common presentation is the monoarticular variety. It usually affects the hip and the knee joint $[38,39]$. The first clinical finding may be an effusion associated with a synovial hypertrophy and the differential diagnosis includes septic arthritis, Lyme disease, hemophilia, pigmented villondular synovitis, and juvenile rheumatoid arthritis.

Radiographically, there is soft tissue swelling and diffuse osteopenia, without a focal abnormality. The first bony changes are marginal erosions followed by erosion of the articular cartilage and of the underlying bone, resulting in loss of joint space and finally causing degeneration of the joint [Fig 21a,21b].The early 
findings on magnetic resonance imaging are nonspecific, and include a joint effusion, marrow edema, and during the stage of arthritis there may be abnormalities within the articular cartilage and subchondral bone $[40,41][$ Fig 21c]

\section{Spondylitis :}

.The disease typically involves the thoracic and thoracolumbar spine, although any region may be affected, and "skip lesions" occur rarely. The most common presentation is paradiscal involving bony destruction adjacent to the end plates of two or more vertebral bodies [10]. Involvement of the disc manifests as collapse of the intervertebral disc space [32]. Paravertebral abscesses form early and are easily seen in the thoracic region as posterior mediastinal masses. Paravertebral psoas abscess in the lumbar spine can produce significant paraspinal soft-tissue opacity. The psoas abscess may extend into the groin and thigh.

While plain radiographs are sufficient to establish the diagnosis, more advanced imaging is required in patients presenting early in their course of symptoms [Fig 22a]. CT is of great value in demonstrating a small focus of vertebral involvement. MR imaging of the spine is also useful in diagnosing tuberculosis spondylitis. Typical findings include a focal area of decreased signal intensity on T1-weighted image and increased signal intensity on T2-weighted images. With involvement of the disk, increased signal intensity is noted within the disk space [42][Fig 22b, 22c].

The most important differential diagnosis is pyogenic vertebral osteomyelitis. Other entities that may mimic tuberculous spondylitis include vertebral body metastases, sarcoidosis, primary vertebral neoplasm (lymphoma, multiple myeloma, chordoma), and rarely infections such as brucellosis, fungal disease, and echinococcosis [42]

\section{Genitourinary Tuberculosis}

Excretory urography has contributed greatly to the diagnosis of urinary tuberculosis. However CT, MRI, and sonography are required for evaluating patients with genitourinary tuberculosis because these techniques can provide information regarding changes in the renal parenchyma, adjacent organs, and genital organs that is not available on excretory urography [43]

\section{Renal tuberculosis}

The radiological findings in renal TB depend on the extent of the disease process. The collecting system is the most common site of urinary tuberculosis. Conventional abdominal radiographs usually demonstrates various patterns of calcifications. IVU remains the initial imaging of choice in most patients. The earliest radiographical abnormality is irregularity of the calyx due to papillary necrosis. Infundibular stricture results in calyceal dilatation [Fig 23]. The entire calyx may not be seen if the infundibular stricture is complete. The renal pelvis is typically small and contracted [44]. The last product of inadequately treated tuberculosis is dystrophic calcifications involving both entire kidneys, known as "putty kidney"[45] [Fig 24]

Computed tomography (CT) is the most sensitive method to demonstrate renal calcification, the extent of renal and extrarenal spread of disease. Other CT features include parenchymal scarring, low-attenuation parenchymal lesions and hydronephrosis. However, early uroepithelial mucosal change is better demonstrated by urography than CT. Ultrasonography (US) is useful in measuring the renal size and showing the dilated calyces with irregular walls and debris.[3,46]

\section{Ureteric Tuberculosis}

Ureteric TB is the result of renal TB that spreads down the collecting systems from the renal pelvis. Earliest feature of ureteric TB is ulcerations causing mucosal irregularity healing of which results in ureteric fibrosis. Multiple strictures may produce alternating segments of dilatation and narrowing, giving a beaded appearance which is the characteristic appearance of ureteric TB. The lesions may be demonstrated on IVU, retrograde or antegrade pyelography [21]

\section{Bladder and Urethra}

Early TB cystitis produces mucosal ulceration and oedema. The involved bladder becomes distorted, ragged, and, finally shrunken described as thimble bladder [Fig 25a,25b]. Urography or US may demonstrate diffuse irregular wall thickening. Therefore, the most common manifestation of TB cystitis is a reduced bladder capacity with wall thickening. CT or MRI shows wall thickening and shrinkage. Advanced bladder involvement also may be complicated by vesicoureteral reflux due to fibrosis at the ureteral orifice [45].

Ureterovesical reflux may also be seen due to gaping of the ureteric orifice secondary to fibrosis in the region of the trigone. Calcifications of the bladder wall are rare, if found must be differentiated from other causes of bladder calcifications, such as schistosomiasis of bladder, cytoxan cystitis, radiation-induced bladder calcification, calcified bladder carcinoma, or encrusted foreign body [21]. 


\section{Genital Tuberculosis}

Genital tuberculosis affects both males and females. In female genital tuberculosis include endometrial adhesions leading to obliteration of the endometrial cavity, obstruction of the fallopian tubes with multiple strictures giving it beaded appearance [Fig 26a, 26b]. Spread from TB salpingitis can cause peritonitis, endometriosis, or rarely, cervicitis and vaginitis. Hysterosalpingography is recommended to identify the lesions [21]. Advanced tuberculous endometritis may mimic severe uterine adhesions as seen in Asherman syndrome [Fig 27].

TB involvement of the prostate and seminal vesicles are usually secondary to infection from the upper genitourinary tract and may cause a variety of changes such as necrosis, calcification, caseation, and cavitation [Fig 28a,28b]. Tuberculous epididymo-orchitis occurs either from haematogeneous spread or retrograde extension from the prostate and seminal vesicles. On US it appears as focal or diffuse areas of decreased echogenicity with epididymal involvement [21]. Other US features of scrotal TB include thickened scrotal skin, hydrocoele calcifications of the epididymis and tunica vaginalis, scrotal abscesses, and scrotal sinus tract.

\section{Adrenal tuberculosis}

\section{Rare forms of tuberculosis}

Adrenal tuberculosis is usually rare. Its involvement manifests as unilateral or bilateral adrenal masses with central areas of necrosis [Fig 29]. When the disease is treated adequately, adrenal atrophy with calcification may be seen [47].The radiologic differential diagnosis includes metastases, primary adrenal neoplasm, and adrenal hemorrhage[3].

\section{Ocular tuberculosis}

Ocular tuberculosis may involve any part of the eye. Chorioretinitis and uveitis are the most common manifestations . Unilateral choroidal mass is the usual presentation at CT and MR imaging. Sometimes it may extend to involve the adjacent bone resulting in skull vault tuberculosis [Fig 30a,30b,30c].The differential diagnosis for ocular tuberculosis includes melanoma, metastasis, hemangioma, sarcoidosis, and systemic mycoses[3].

\section{Cardiac tuberculosis}

Cardiac involvement is very rare. It may occur secondary to mediastinal or pulmonary tuberculosis [Fig 31]. Rarely it may result in calcific pericarditis [48].

\section{Chest Wall Tuberculosis}

Chest wall tuberculosis may occur secondary to pleural disease, empyema or by hematogenous spread of disease. It usually presents with destruction of bone or costal cartilage. On contrast-enhanced images soft tissue masses with calcification or rim enhancement may be demonstrated [49][Fig 32]. Sometimes fistulization to skin may occur.

\section{Tuberculous otomastoiditis}

Tuberculous otomastoiditis usually result from direct extension from the upper respiratory tract or from hematogenous spread [50]. During early stages soft-tissue attenuation is noted in the tympanic cavity on CT images. Destruction of middle ear structures may be noted in the later stages. Associated retroauricular or epidural abscess may also be seen. The differential diagnosis for tuberculous otomastoiditis includes pyogenic or fungal infection, sarcoidosis, cholesteatoma, and Wegener granulomatosis [3].

\section{Figures}

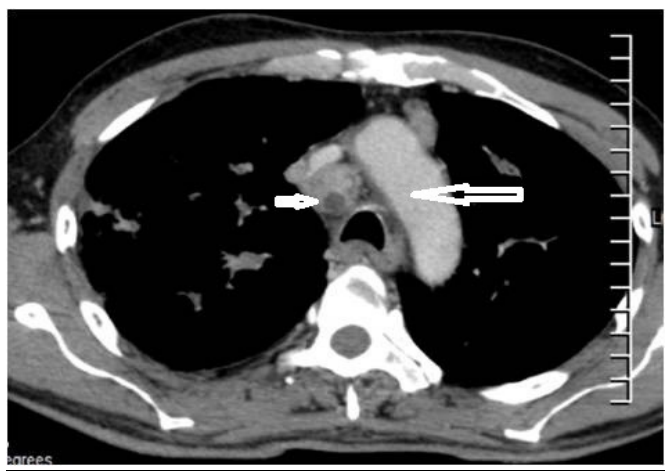

Fig 1 : Tubercular lymphadenopathy : Enlarged enhancing paratracheal lymph node with central caseous necrosis (arrow). 

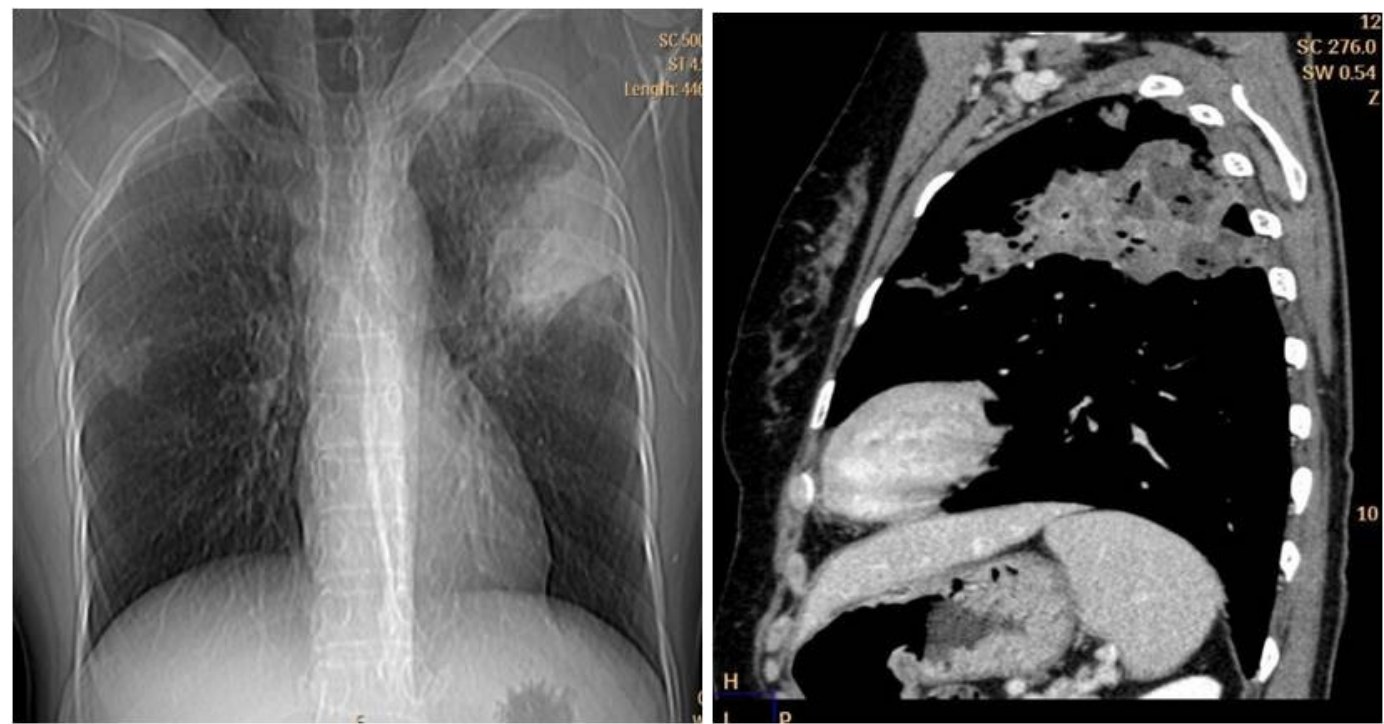

Fig $2 \mathrm{a}$ and $2 \mathrm{~b}$ : Consolidation : a) Radiograph showing a well defined radioopacity suggestive of consolidation in left upper zone. b) Corresponding CT scan confirms the diagnosis of consolidation involving the left upper lobe

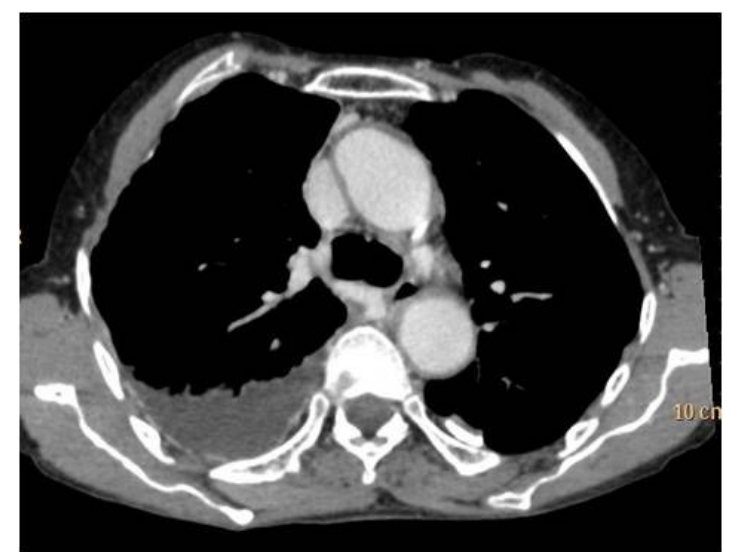

Fig 3 : Pleural effusion : Axial CT scan image showing right sided pleural effusion

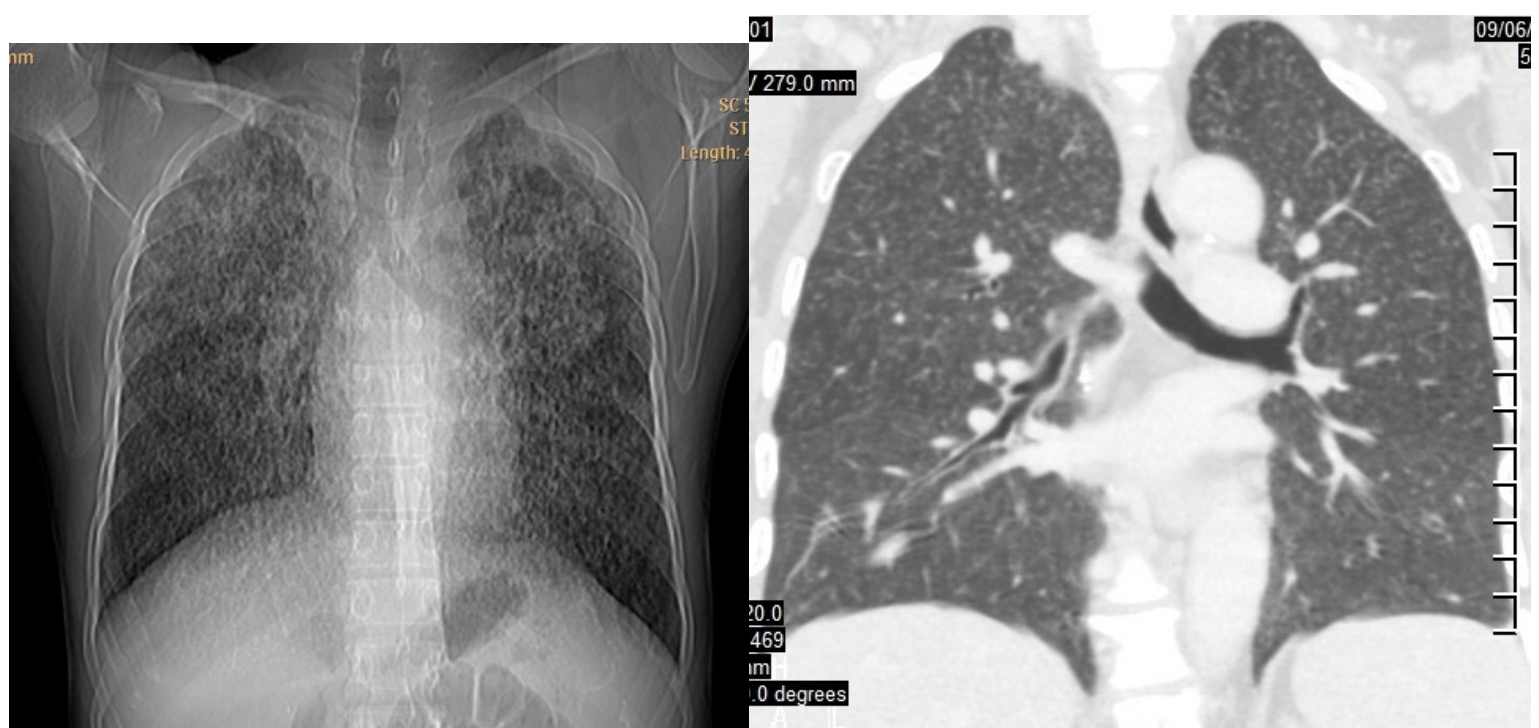

Fig 4a and $4 \mathrm{~b}$ : Miliary Tuberculosis : a) Radiograph showing numerous tiny opacities scattered throughout bilateral lung zones. b) Corresponding CT scan image shows numerous tiny nodular opacities involving bilateral lungs. 


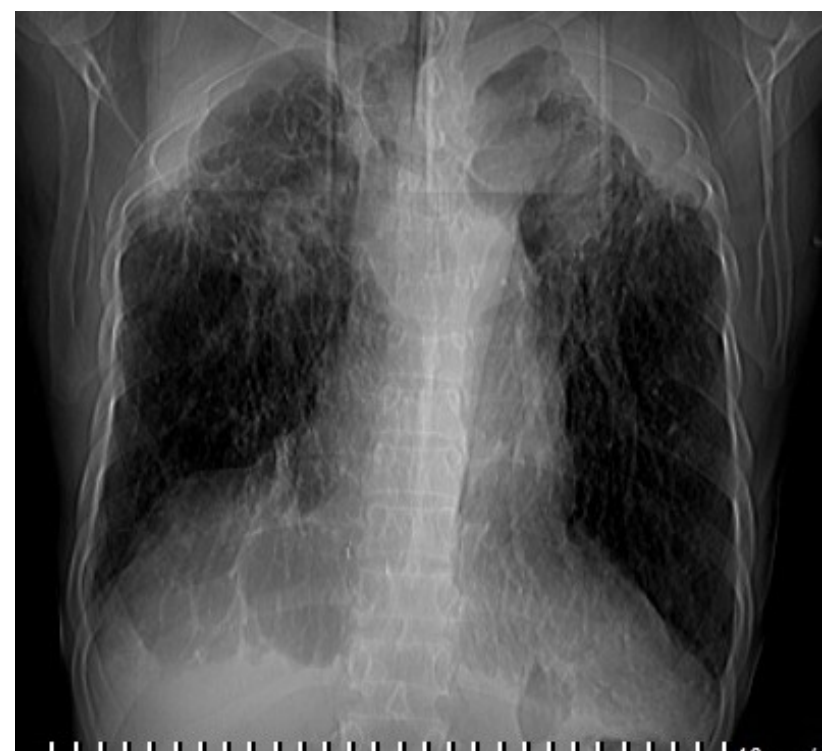

Fig 5a,: Postprimary Tuberculosis : a) Radiograph showing fibrocavitatory changes bilateral upper zones.

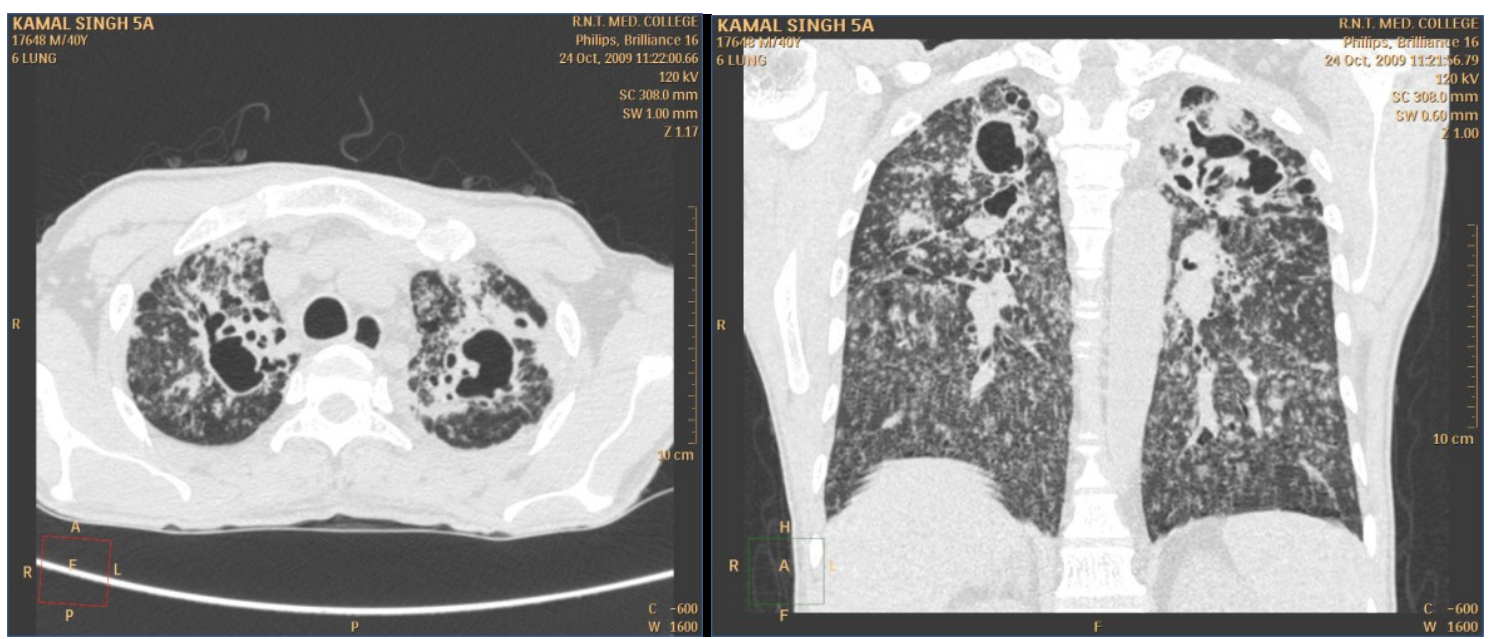

Fig 5b,5c) Postprimary Tuberculosis : Corresponding axial and coronal CT scan image demonstrating thick irregular walled cavity with surrounding consolidation and fibrosis with tractional bronchiectasis.

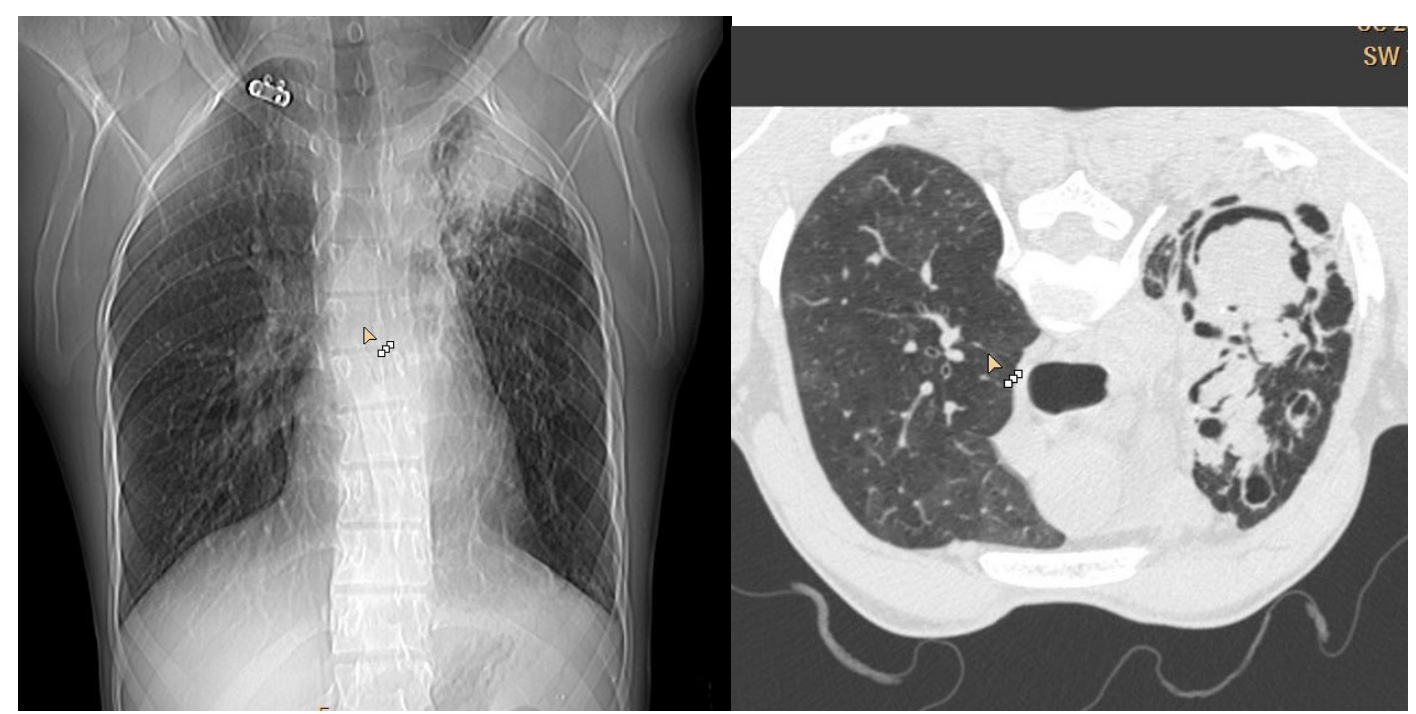

Fig $6 a$ and $6 b$ : Fungal ball : a) Radiograph showing a cavity with fungal ball and air crescent sign in left upper zone. b) Corresponding axial CT scan of the same patient in prone position shows the shifting of the fungal ball in the dependent position with air crescent sign. 


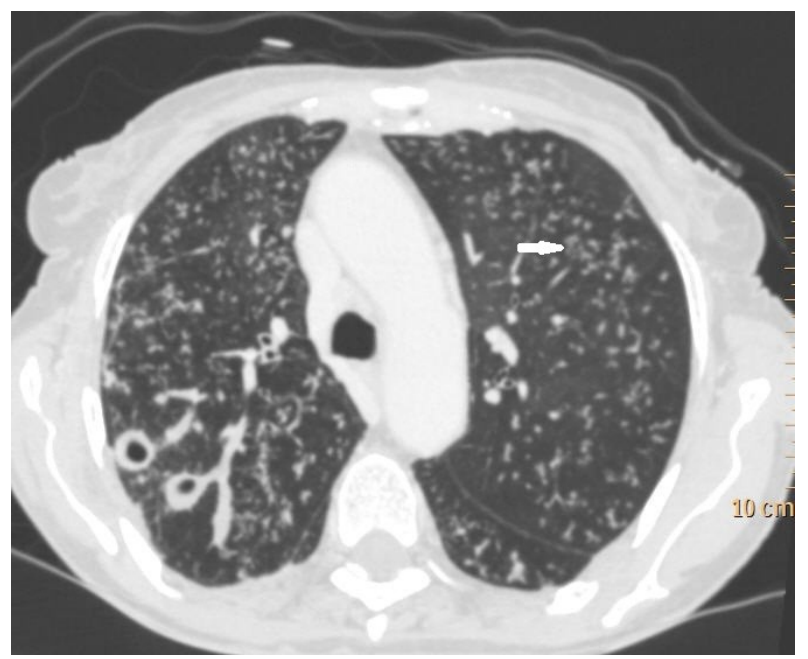

Fig 7 : Tree in bud pattern : Axial CT scan image shows branching linear opacities (arrow) predominantly in the peripheral lung fields suggestive of endobronchial spread of infection.

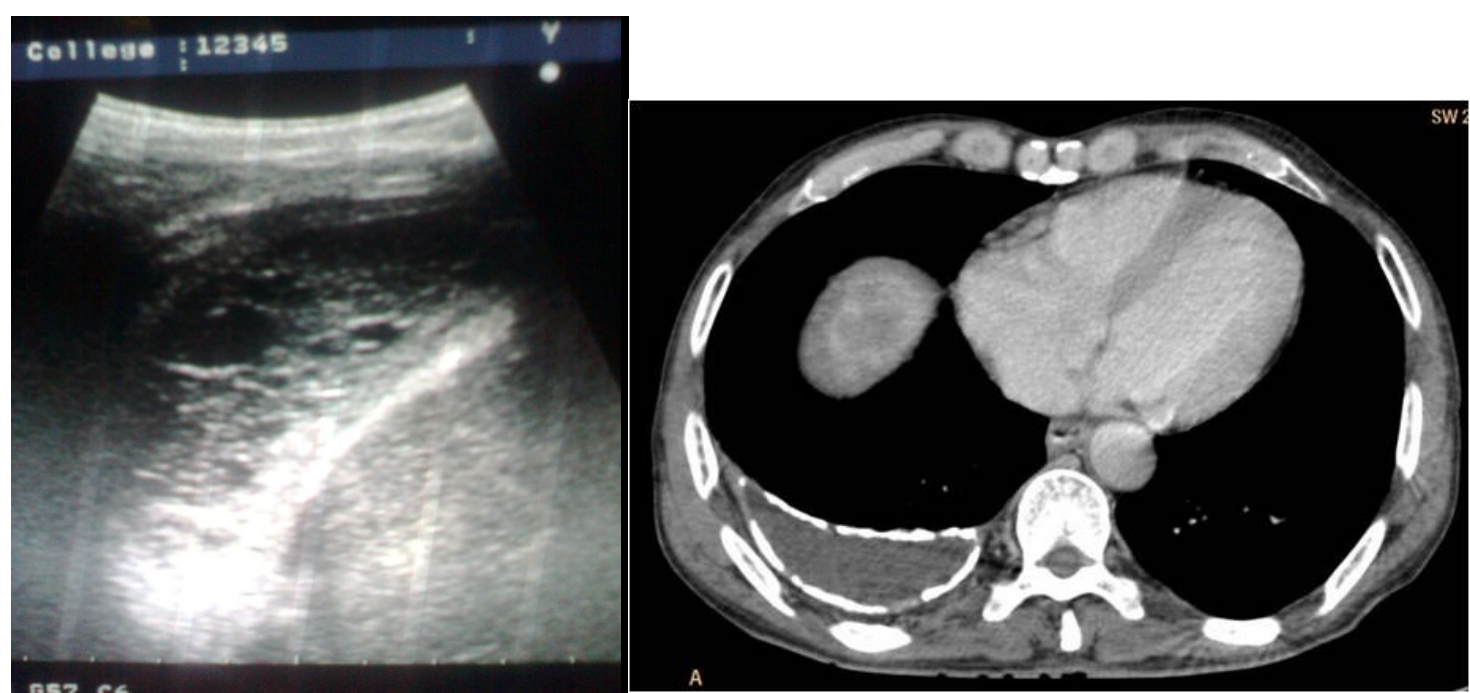

Fig 8a and 8b : Empyema : a) USG image showing fluid collection with internal septations in right pleural space. b) Axial CT scan image showing fluid collection the right pleural space with peripheral calcification suggestive of a chronic empyema.

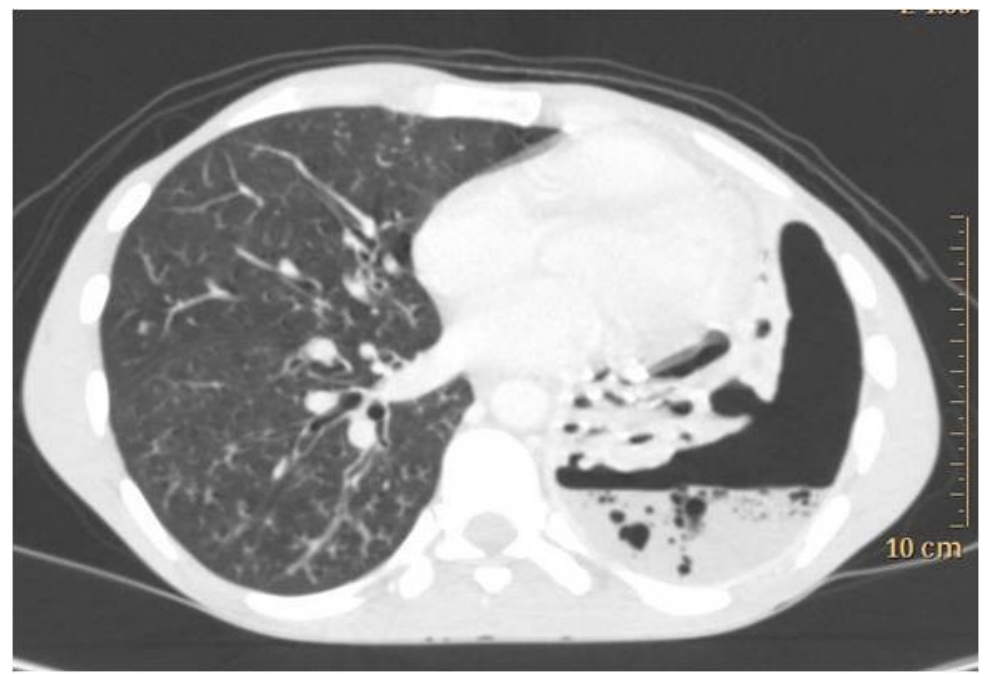

Fig 9 : Bronchopleural fistula : Axial CT scan image showing completely destroyed left lung with one of the bronchi showing communication with the pleural space containing fluid and air locules suggestive of a bronchopleural fistula 


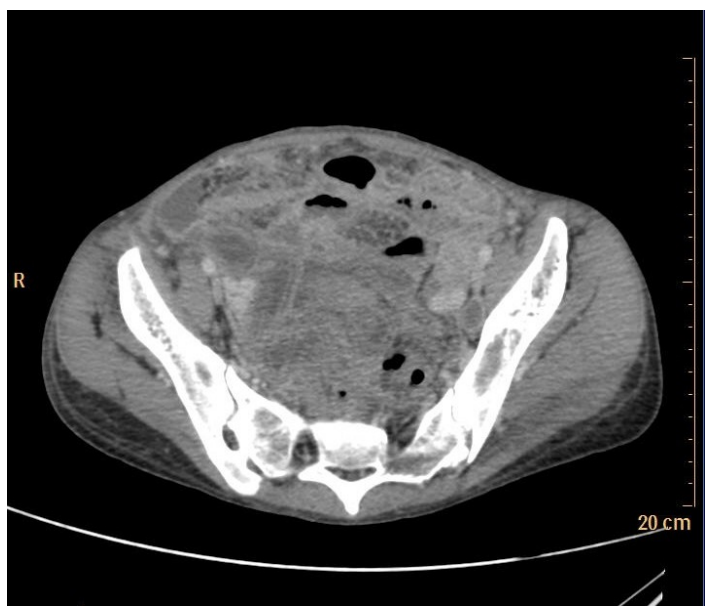

Fig 10 : Tuberculous peritonitis, Wet type : Axial CT scan showing loculated ascites showing slightly higher attenuation

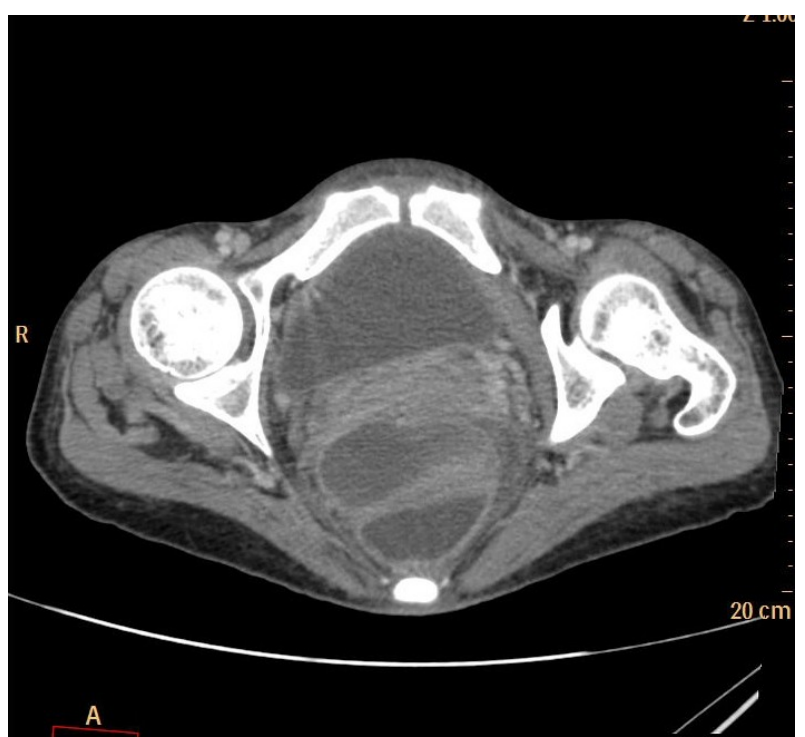

Fig 11 : Tuberculous peritonitis, fibrotic type : Axial CT scan showing thickened mesentry with matted bowel loops and loculated ascites.

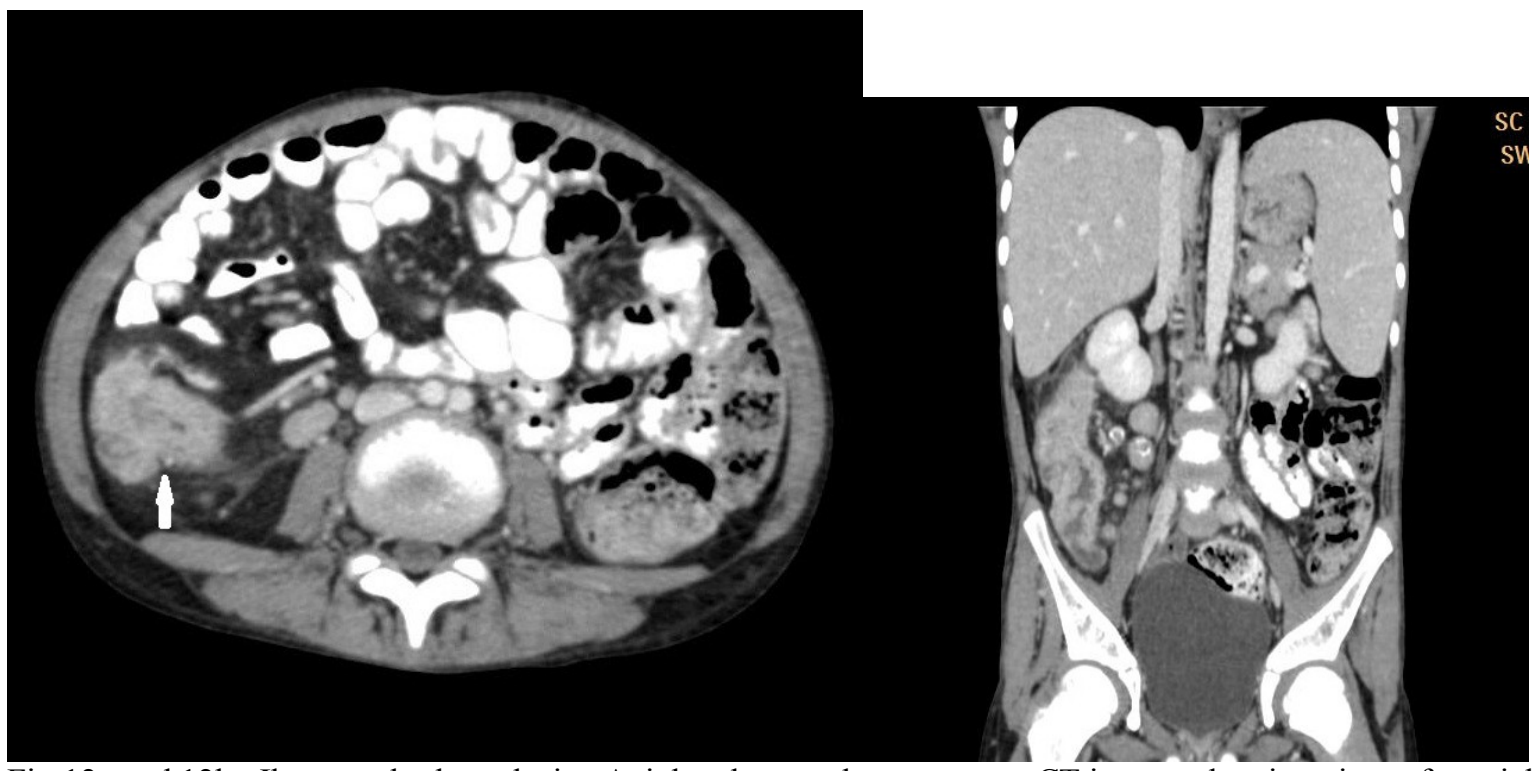

Fig 12a and 12b : Ileocaecal tuberculosis : Axial and coronal postcontrast CT images showing circumferential mural thickening of caecum and terminal ileum (arrow) along with adjacent mesenteric lymphadenopathy 


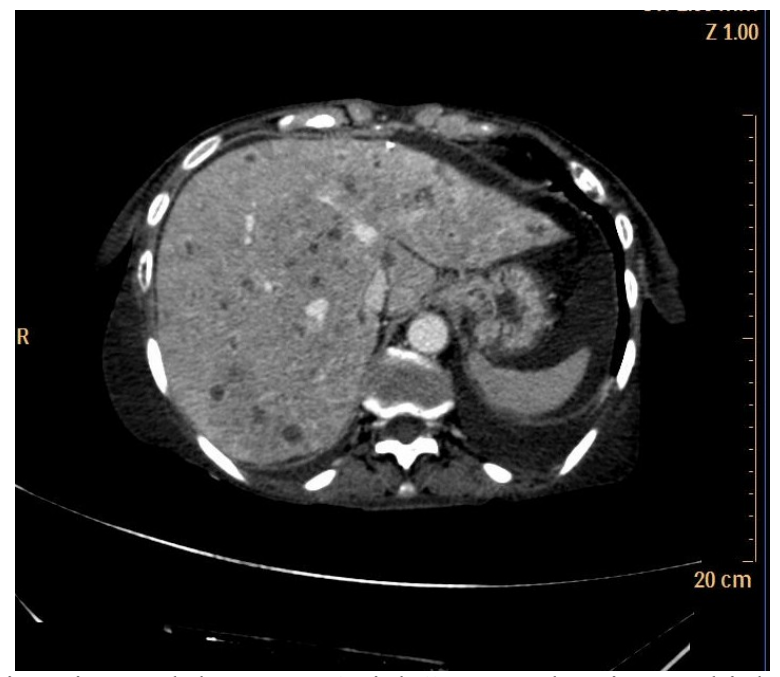

Fig 13 : Hepatic tuberculosis, micronodular type : Axial CT scan showing multiple nodular hypodense lesions of varying sizes involving both the lobes of liver

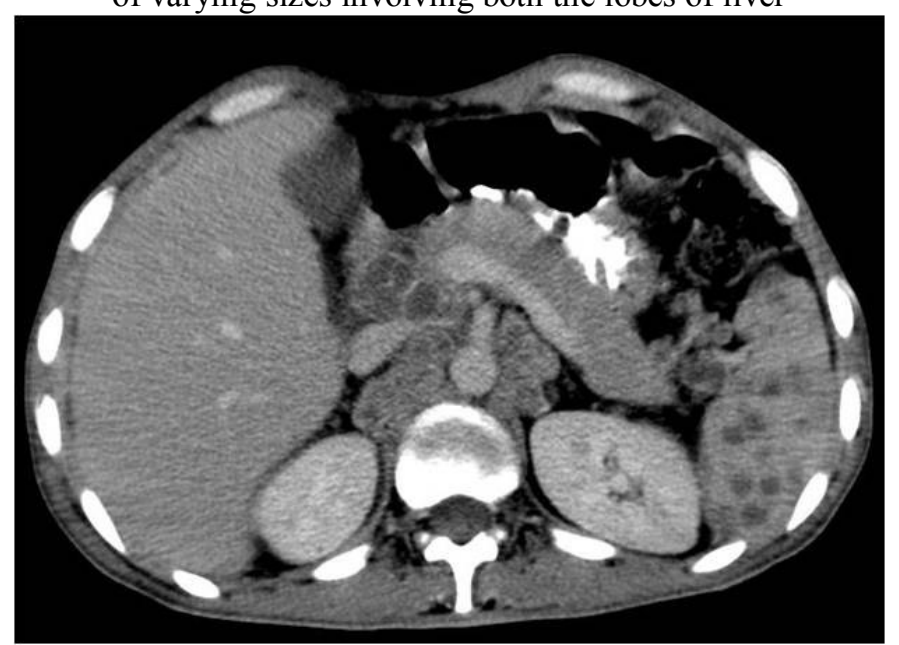

Fig 14 : Splenic tuberculosis : Axial CT scan showing multiple small nodular hypodense lesions in the spleen

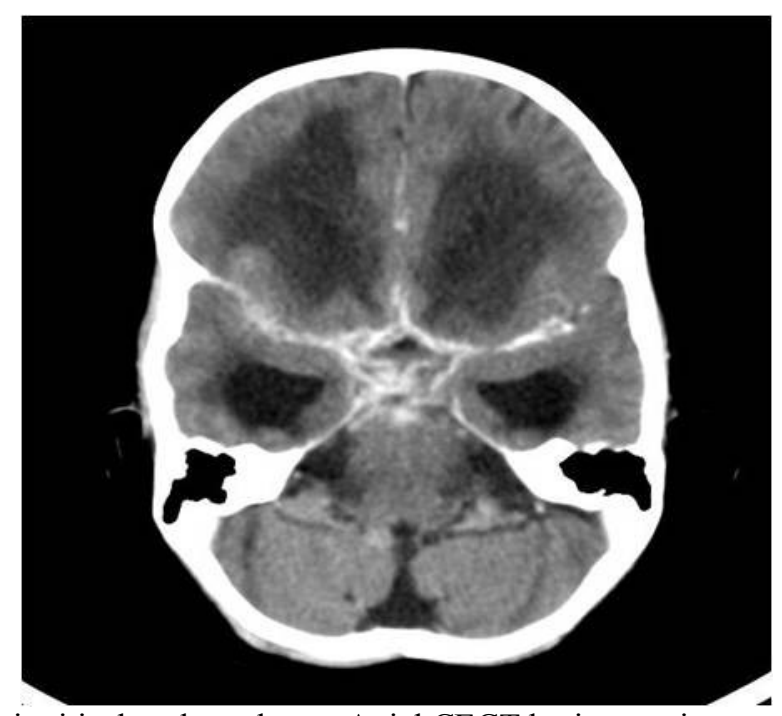

Fig 15 : Tubercular meningitis, basal exudates : Axial CECT brain scan image showing meningitis with hyperdense exudates in the basal cistern and dilated temporal horn of lateral ventricles 


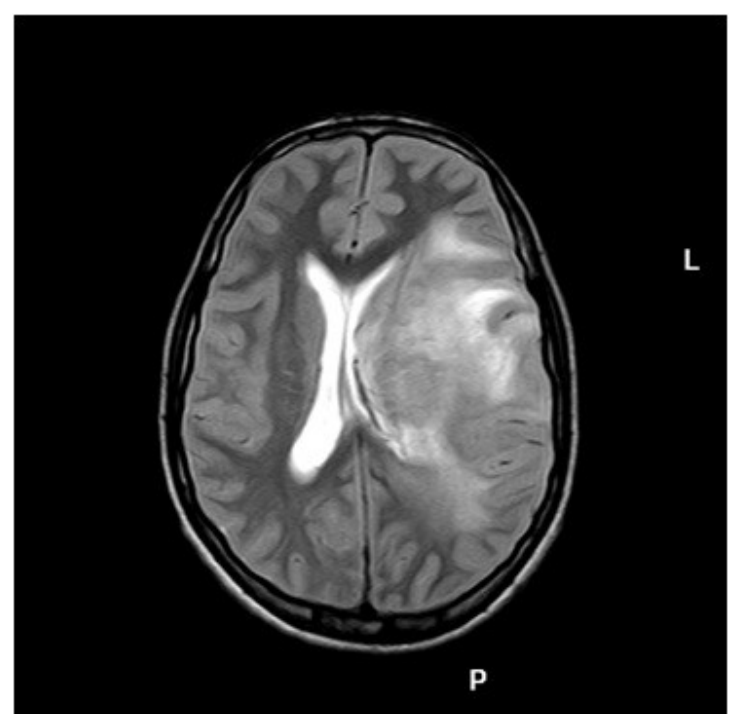

Fig 16 : Tubercular cerebritis : Axial T2W MR image showing tubercular cerebritis involving left cerebral hemisphere

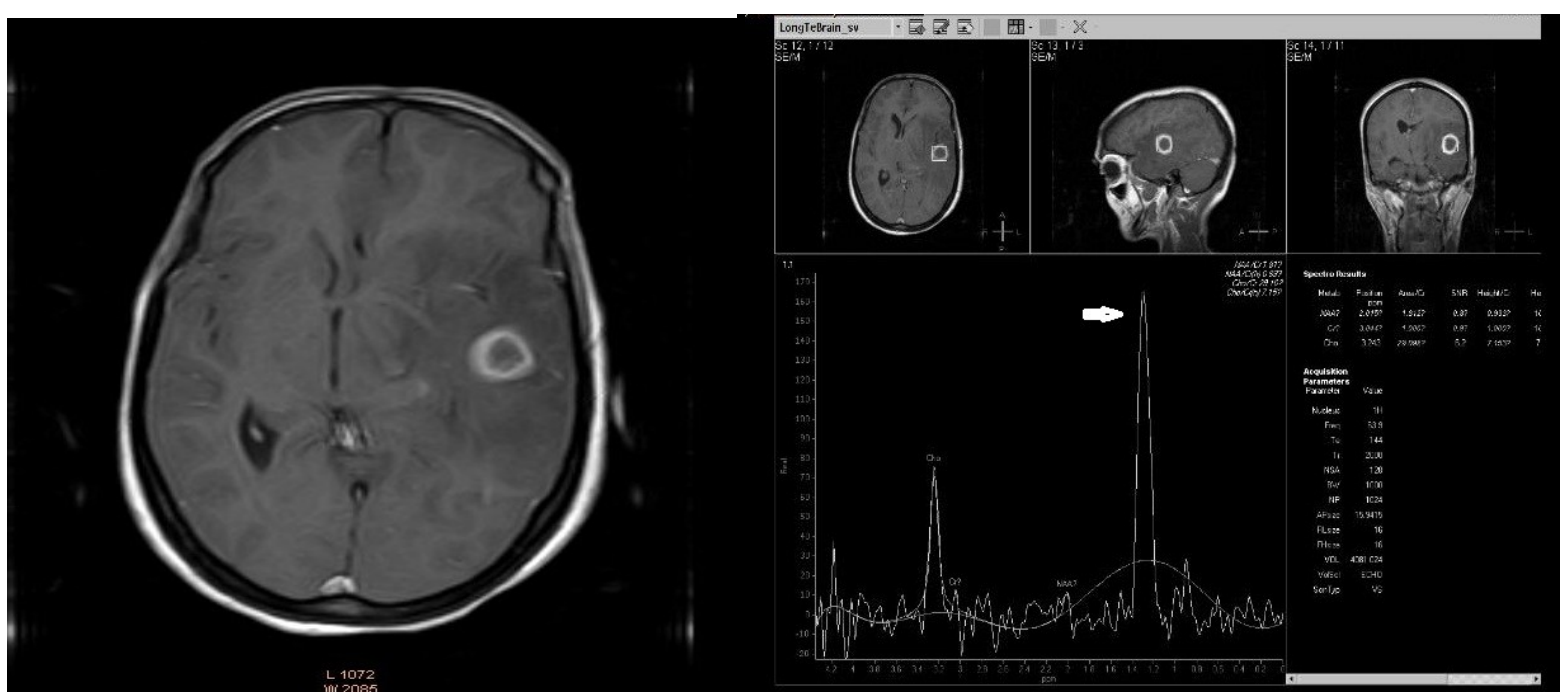

Fig 17a and 17b : Tuberculoma : a) Post gadolinium T1W MR image showing a caseating granuloma with rim enhancement. b) Corresponding MR spectroscopy showing increased lipid peak (arrow) in the necrotic centre

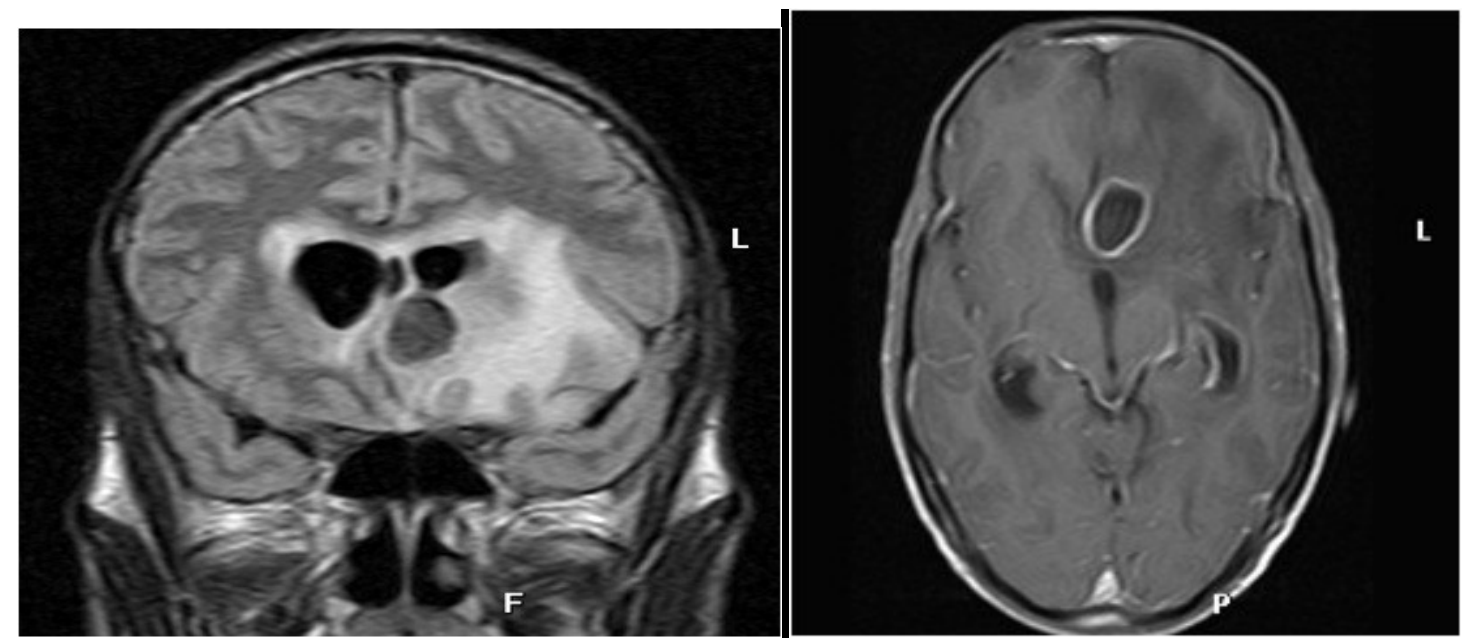

Fig 18a and 18b : Tubercular abscess : Coronal FLAIR and post gadolinium T1W showing tubercular abscess with ventriculitis 


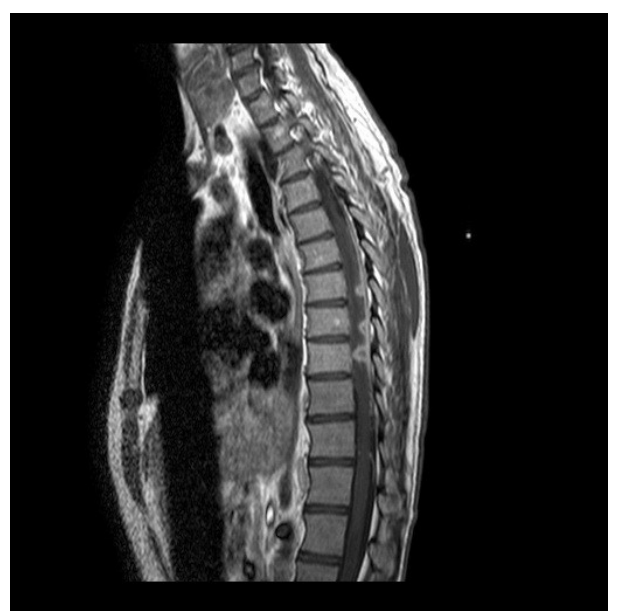

Fig 19 : Spinal tubercular meningitis : Sagittal post contrast MR image showing tubercular granulomas in the spinal cord with arachnoiditis

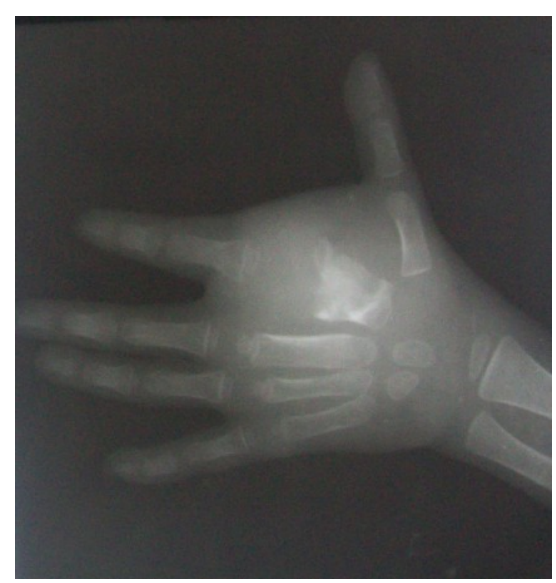

Fig 20 : Spina ventosa : Conventional radiography showing soft-tissue swelling and periostitis along with bony destruction involving the second metacarpal

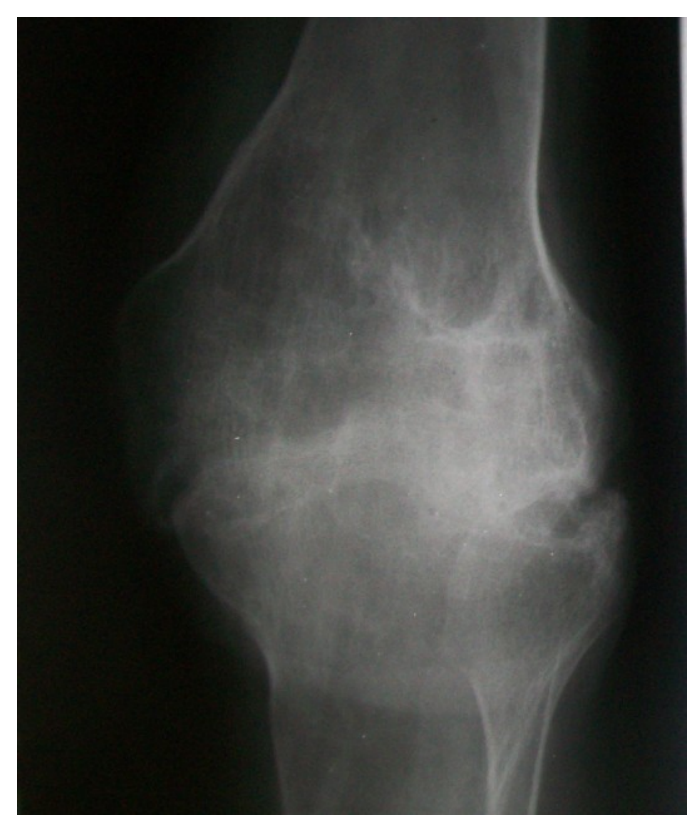

Fig 21a,: Tubercular arthritis : a) Conventional radiograph showing loss of joint space with bony ankylosis involving the knee joint. 


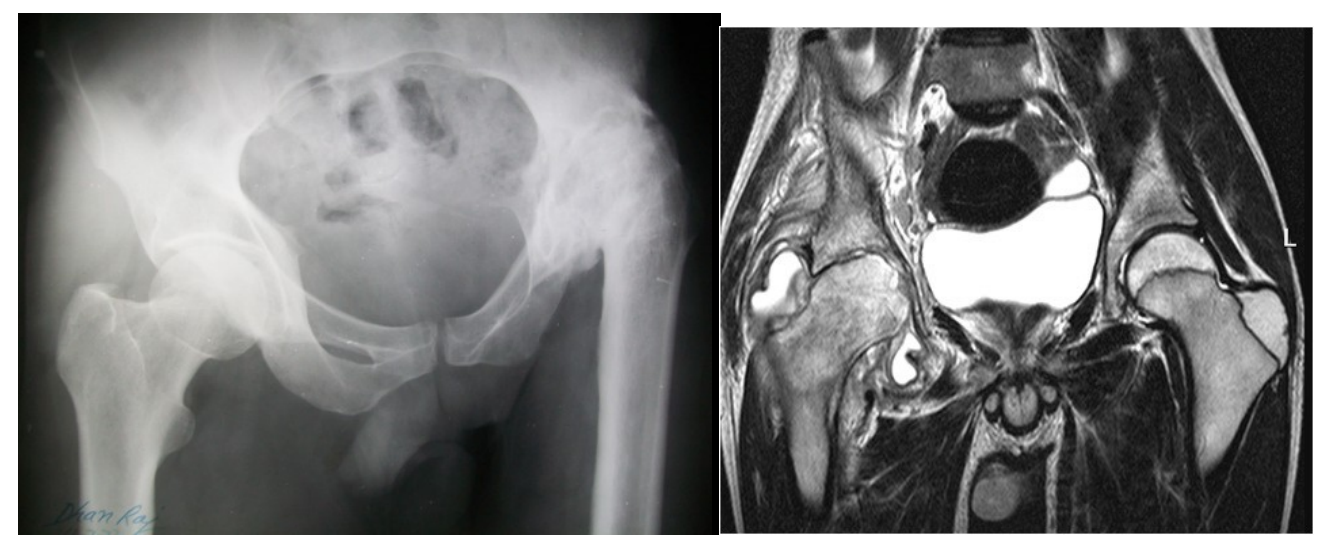

Fig 21b, 21c Tubercular arthritis b) Conventional radiograph showing advanced TB arthritis of left hip resulting in shortening of limb. c) MR T2W image showing irregularities of articular surfaces of the femoral head and the acetabulum with marrow oedema and joint effusion.

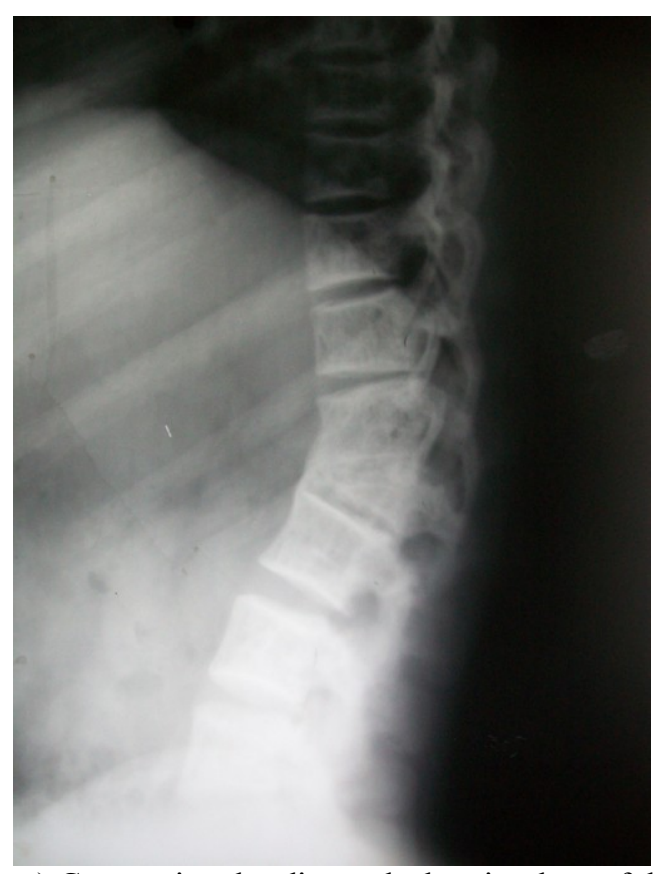

Fig 22a,: Tubercular spondylitis : a) Conventional radiograph showing loss of disc space with destruction of the involved vertebra

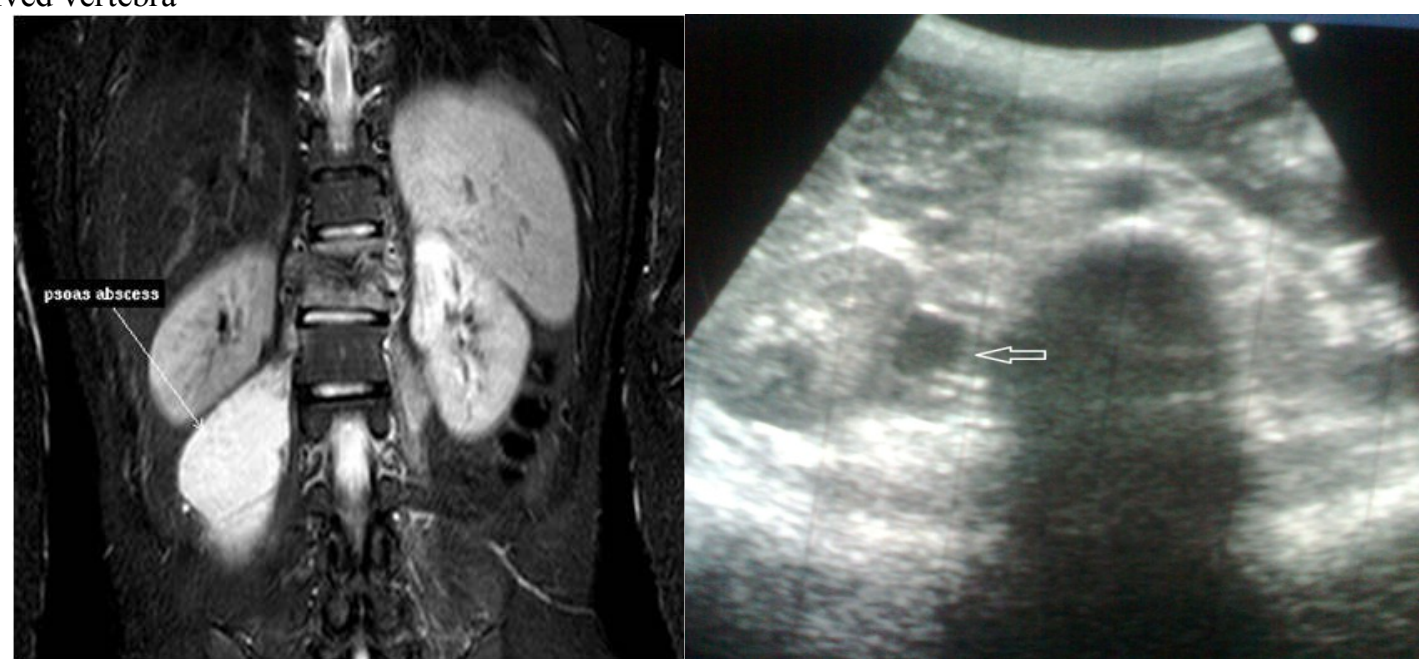

Fig 22b and 22c : Tubercular spondylitis b) MR T2W STIR image showing paradiscal involvement with destruction of adjacent end plates along with right psoas abscess. c) Corresponding USG image showing hypoecoic lesion in the right psoas (arrow) suggestive of abscess 


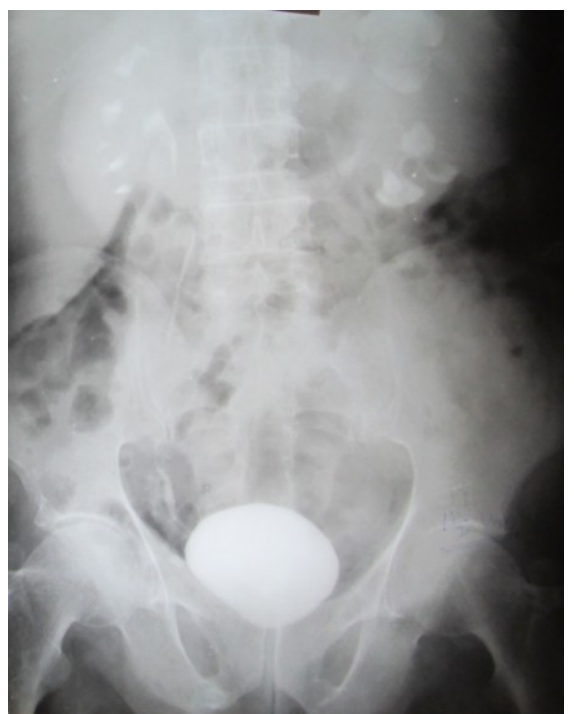

Fig 23 : Renal tuberculosis : Intravenous urogram showing calcifications involving the bilateral renal papillae along with calyceal strictures

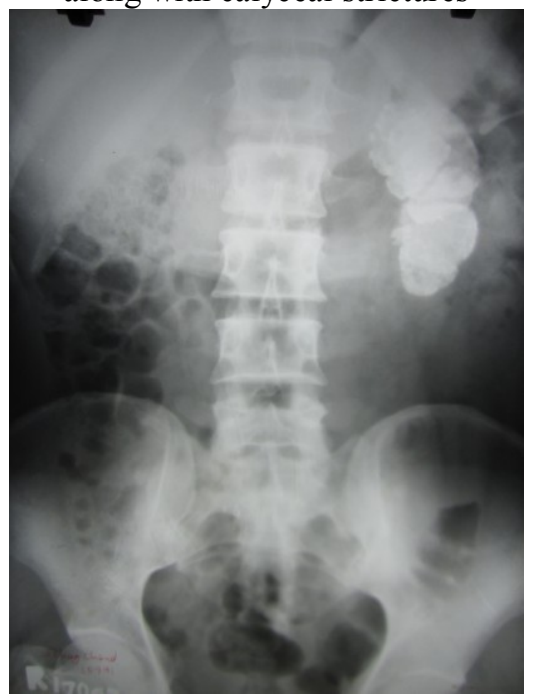

Fig 24 : Putty kidney : Contracted left kidney with dystrophic calcification

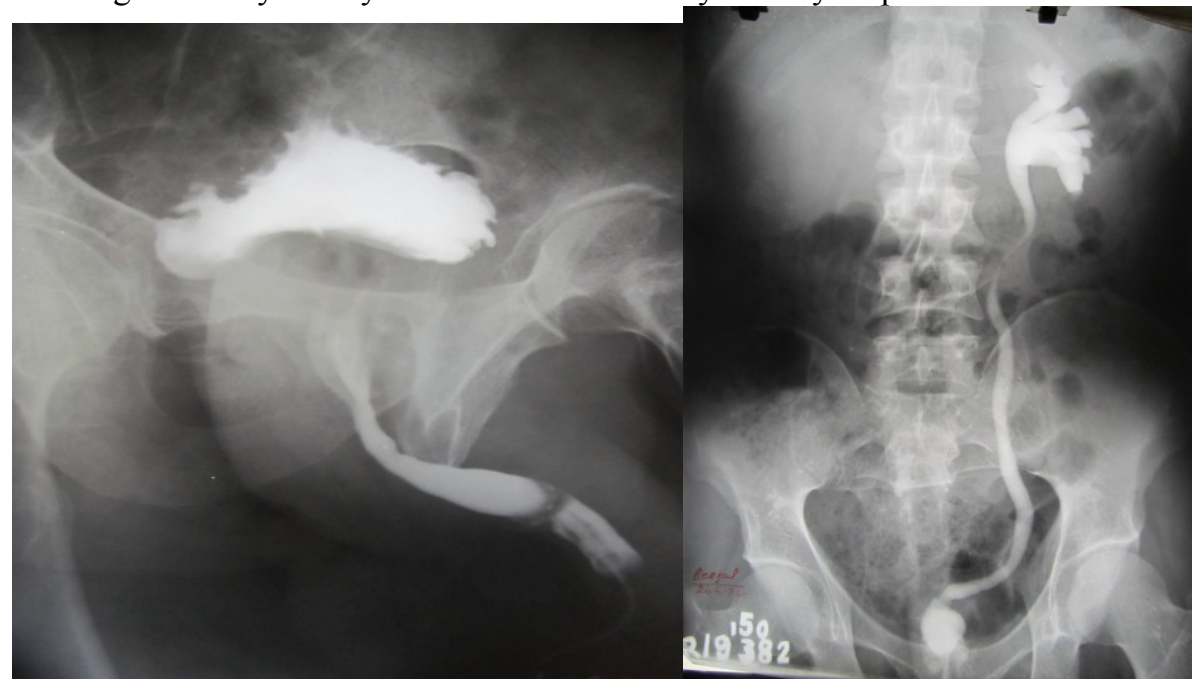

Fig 25a and 25b : Bladder tuberculosis : a) Cystourethrogram showing distorted bladder with ragged and trabeculated wall in early stages of bladder tuberculosis. b) Thimble bladder : Small, contracted bladder with hydroureteronephrosis resulting due to long standing vesicoureteric reflux. 

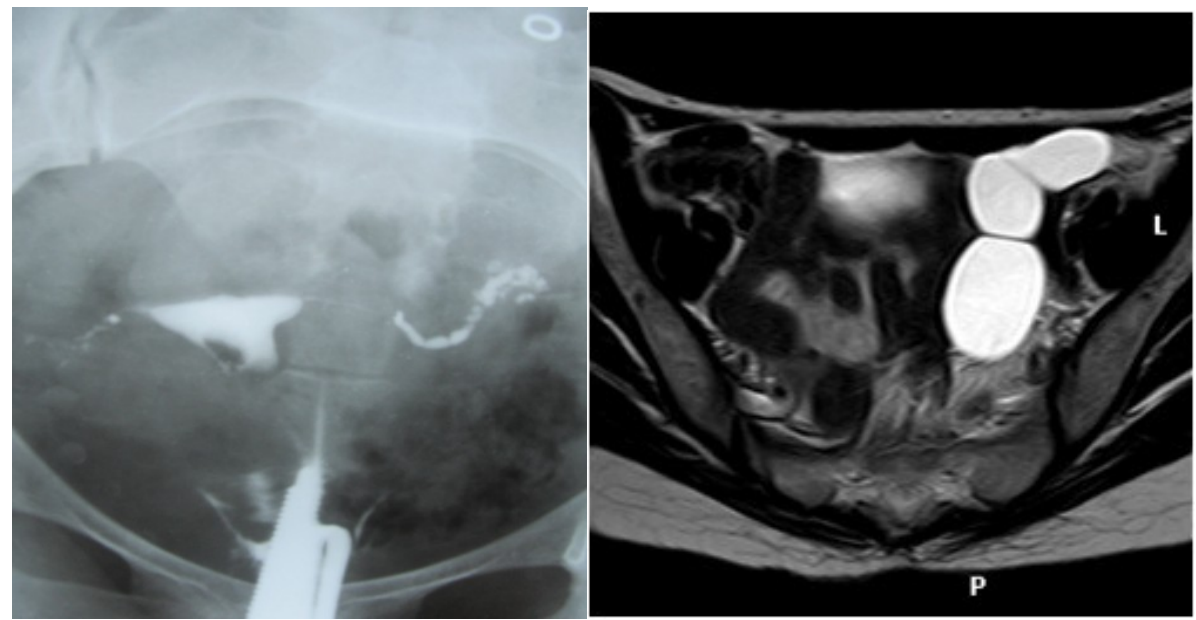

Fig 26a and 26b : Tubercular salpingitis : Hysterosalpingography showing beaded appearance of the fallopian tubes with prominent fimbria suggestive of tobacco pouch appearance. b) MR T2W image showing multiple strictures in the left fallopian tube with hydrosalpinx

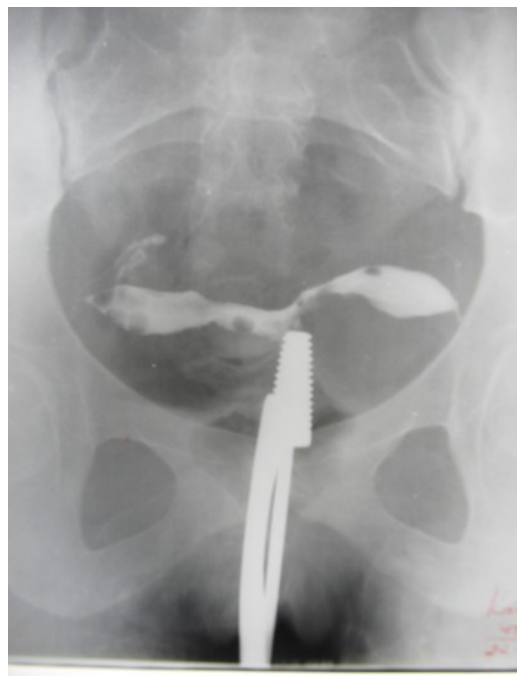

Fig 27 : Hysterosalpingography showing advanced tuberculous endometritis with obliteration of the endometrial cavity with bilateral hydrosalpinx

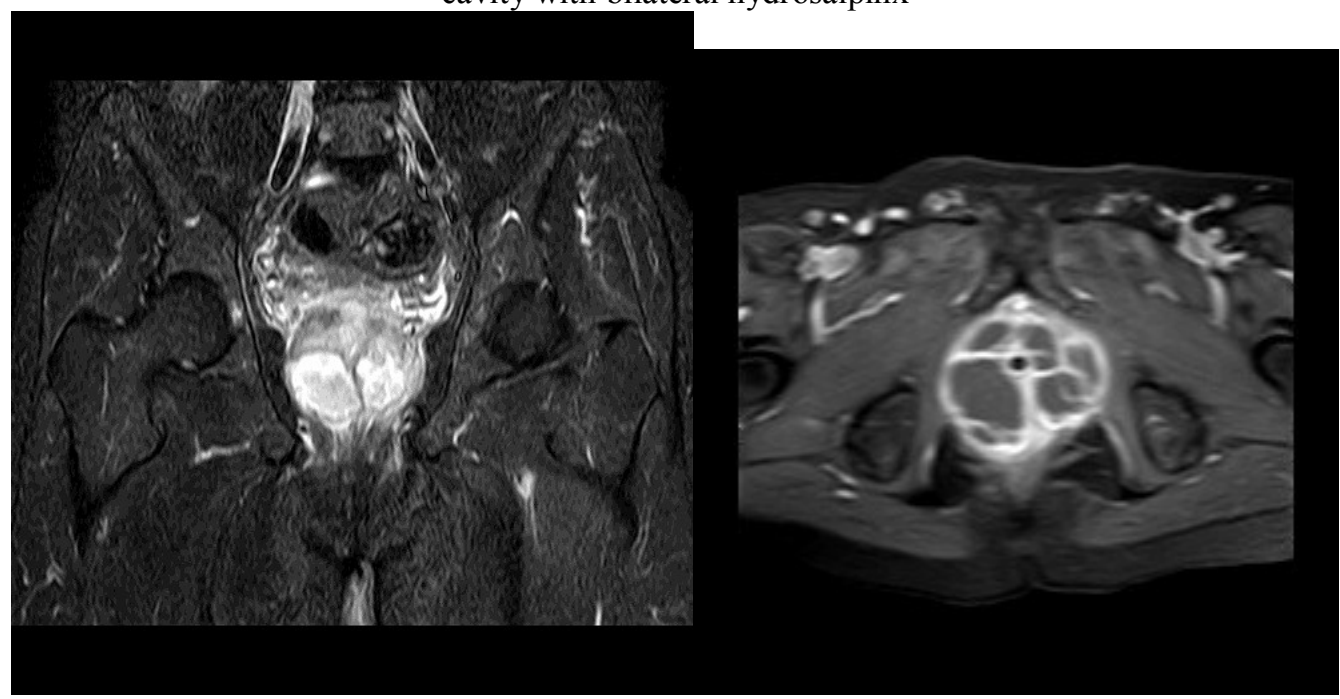

Fig 28a,28b : Tubercular prostatic abscess : a) Coronal fat suppressed MR image showing hyperintense lesions involving the prostate suggestive of tubercular caseous necrosis. b) Axial T1 post gadolinium MR image showing multiple peripherally enhancing hypointense lesions involving the prostate suggestive of prostatic abscesses. 


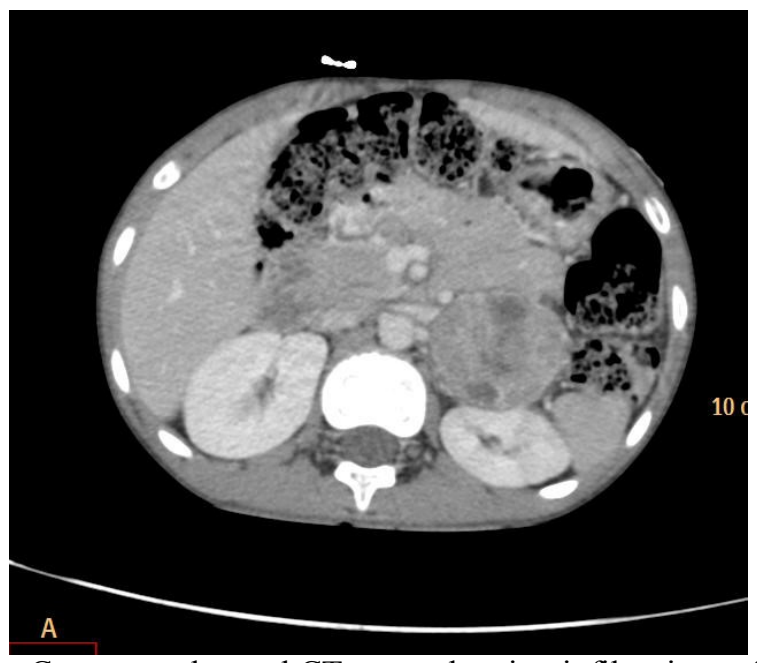

Fig 29 : Adrenal tuberculosis : Contrast-enhanced CT scans showing infiltrating soft tissue mass like lesion with central area of necrosis involving left adrenal gland.

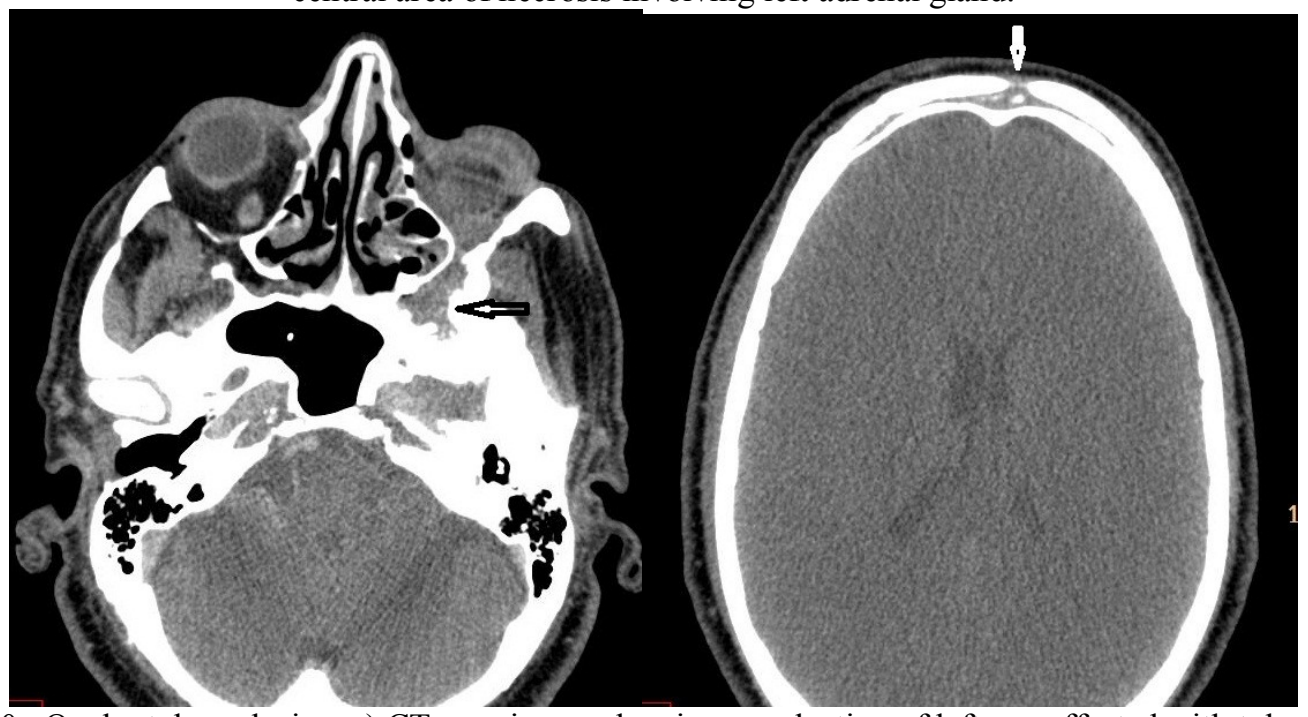

Fig 30 : Ocular tuberculosis : a) CT scan image showing enucleation of left eye affected with tubercular infection. The infective collection is seen extending into the cranial fossa through the superior orbital fissure along with erosion of the adjacent sphenoid bone (arrrow). b) CT scan bone window of the same patient showing tubercular osteomyelitis of the skull vault with sinus formation (arrow).

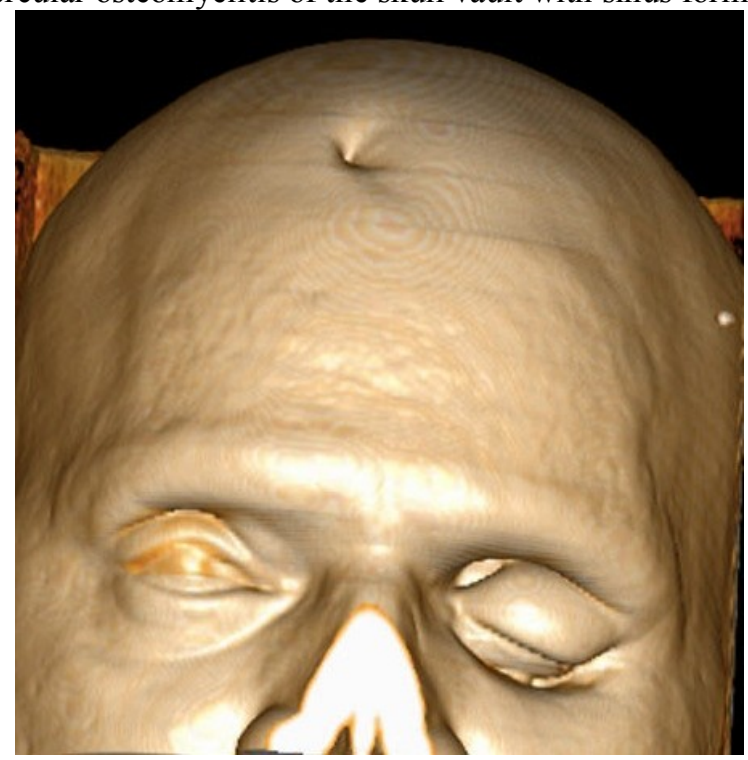

Fig 30c. 3D reconstructed image showing sinuses opening in the frontal region and below the left eyelid. 


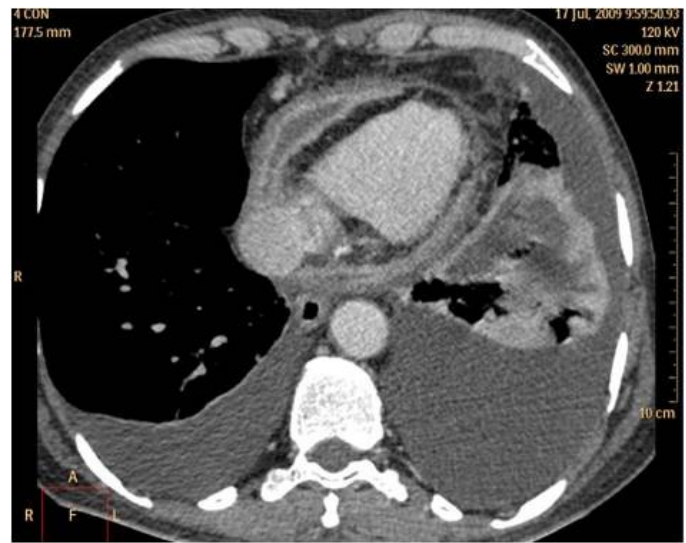

Fig 31 : Cardiac tuberculosis : Contrast-enhanced CT scans showing tubercular pericarditis with minimal pericardial effusion is seen. Bilateral pleural effusion is also seen.

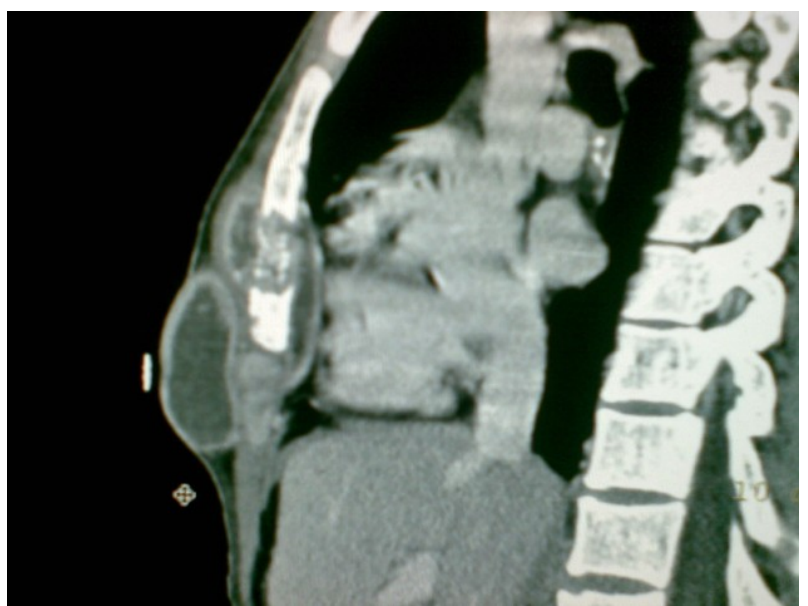

Fig 32 : Chest wall tuberculosis : Contrast-enhanced CT scans shows tubercular osteomyelitis with sequestrum involving the sternum. Tubercular abscess is also noted anterior to the sternum.

\section{Conclusion :}

Tuberculosis is a multisystem disease which can affect any organ system of the body. It is a great mimic of many diseases. Therefore a proper knowledge of the various spectrum of tuberculosis is a must for timely diagnosis and treatment.

\section{References}

[1]. Cegielski JP, Chin DP, Espinal MA, et al. The global tuberculosis situation: progress and problems in the 20th century, prospects for the 21 st century. Infect Dis Clin North Am 2002; 16:1-58.

[2]. Raviglione MC, Snider DE Jr, Kochi A. Global epidemiology of tuberculosis: morbidity and mortality of a worldwide epidemic. J Am Med Assoc 1995; 273:220-226.

[3]. Harisinghani MG, McLoud TC, Shepard JA, Ko JP, Shroff MM, Mueller PR. Tuberculosis from head to toe. RadioGraphics 2000; 20:449-470.

[4]. Leung AN. Pulmonary tuberculosis: the essentials. Radiology 1999; 210:307-322

[5]. Lee KS, Song KS, Lim TH, Kim PN, Kim IY, Lee BH. Adult-onset pulmonary tuberculosis: findings on chest radiographs and CT scans. AJR 1993; 160:753-758.

[6]. Burrill J, Williams CJ, Bain G et al. Tuberculosis: a radiologic review. Radiographics 2007; 27: 1255-73.

[7]. Leung AN, Muller NL, Pineda PR, FitzGerald JM. Primary tuberculosis in childhood: radiographic manifestations. Radiology 1992; 182:87-91.

[8]. Woodring JH, Vandiviere HM, Fried AM, Dillon ML, Williams TD, Melvin IG. Update: the radiographic features of pulmonary tuberculosis.AJR 1986; 146:497-506.

[9]. Kwong JS, Carignan S, Kang E, Muller NL, FitzGerald JM. Miliary tuberculosis: diagnostic accuracy of chest radiography. Chest $1996 ; 110: 339-342$

[10]. Im JG, Itoh H, Han MC. CT of pulmonary tuberculosis. Semin Ultrasound CT MR 1995; 16: 420-434.

[11]. Rossi SE, Franquet T, Volpacchio M, Gimenez A, Aguilar G. Tree-in-bud pattern at thin-section CT of the lungs: radiologicpathologic overview. RadioGraphics 2005; 25: 789-801.

[12]. Collins J, Blankenbaker D, Stern EJ. CT patterns of bronchiolar disease: what is "tree-in-bud"? AJR Am J Roentgenol 1998; 171:365-370.

[13]. Moon WK, Im JG, Yeon KM, et al. Tuberculosis of the central airways: CT findings of active and fibrotic disease. AJR Am J Roentgenol 1997; 169:649-653. 
[14]. Lam KY, Lo CY.A critical examination of adrenal tuberculosis and a 28 -year autopsy experience of active tuberculosis. Clin Endocrinol (Oxf) 2001; 54(5):633-639.

[15]. Engin G, Acunas B, Acunas G, Tunaci M. Imaging of extrapulmonary tuberculosis. RadioGraphics 2000;20(2):471-488.

[16]. Suri S, Gupta S, Suri R. Computed tomography in abdominal tuberculosis. Br J Radiol 1999; 72(853):92-98.

[17]. LuceyBC, Stuhlfaut JW, Soto JA. Mesenteric lymph nodes: detection and significance on MDCT. AJR Am J Roentgenol 2005; 184:41-44.

[18]. Ha HK, Jung JI, Lee MS, Choi BG, Lee GM, Kim YH, et al. CT differentiation of tuberculous peritonitis and peritoneal carcinomatosis. AJR Am J Roentgenol 1996; 167:743-748.

[19]. Akhan O, Pringot J. Imaging of abdominal tuberculosis.Eur Radiol 2002; 12:312-323.

[20]. Leder RA, Low VH. Tuberculosis of the abdomen. Radiol Clin North Am 1995; 33:691-705.

[21]. Nagi B, Kochhar R, Bhasin DK, Singh K. Colorectal tuberculosis. Eur Radiol 2003; 13:1907-1912.

[22]. Jadvar R, Mindelzun RE, Olcott EW, Levitt DB. Still the great mimicker: abdominal tuberculosis. AJR Am J Roentgenol 1997; 168:1455-1460.

[23]. Malde HM, Chadha D. The "cluster" sign in macronodular hepatic tuberculosis: CT features. J Comput Assist Tomogr 1993; 17:159-161.

[24]. Levine C. Primary macronodular hepatic tuberculosis: US and CT appearances. Gastrointest Radiol 1990; 15:307-309.

[25]. Ravindra Kumar Garg. Tuberculosis of the central nervous system Postgrad Med J 1999 75: 133-140.

[26]. Andronikou S, Smith B, Hatherhill M, Douis H, Wilmshurst J. Definitive neuroradiological diagnostic features of tuberculous meningitis in children. Pediatr Radiol 2004; 34:876-85.

[27]. Bernaerts A, Vanhoenacker FM, Parizel PM, et al. Tuberculosis of the central nervous system: overview of neuroradiological findings. Eur Radiol 2003; 13:1876-90.

[28]. Dastur DK, Udani PM. The pathology and pathogenesis of tuberculous encephalopathy. Acta Neuropathol 1966; 6:311-26.

[29]. Hsieh FY, Chia LG, Shen WC. Locations of cerebral infarctions in tuberculous meningitis. Neuroradiology 1992; 34:197-9.

[30]. Villoria MF, Fortea F, Moreno S et al. MR imaging and CT of central nervous system tuberculosis in the patient with AIDS. Radiol Clin North Am 1995; 33:805-820

[31]. Mukesh GH, Theresa CM, Jo-Anne OS, Jane PK, Manohar MS, Peter RM. Tuberculosis from Head to Toe. March 2000 RadioGraphics, 20, 449-470.

[32]. de Castro CC, de Barros NG, Campos ZM, Cerri GG. CT scans of cranial tuberculosis. Radiol Clin North Am 1995; 33:753-69.

[33]. Arbeláez A, Medina E, Restrepo F, Castillo M. Cerebral tuberculosis. Semin Roentgenol 2004; 39:474-81.

[34]. JLS Khoo, KY Lau, CM Cheung, TH Tsoi. Central Nervous System Tuberculosis. J HK Coll Radiol 2003;6:217-228

[35]. De Vuyst D, Vanhoenacker F, Gielen J, Bernaerts A, De Schepper AM. Imaging features of musculoskeletal tuberculosis Eur Radiol. 2003 Aug; 13(8):1809-19. Epub 2002 Aug 2.

[36]. Spiegel DA, Singh GK, Banskota AK. Tuberculosis of the musculoskeletal system. Techniques in Orthopaedics 20:167-178, 2005.

[37]. Wang MNH, Chen WMC, et al. Tuberculous osteomyelitis in young children. J Pediatr Orthop 1999; 19:151-155

[38]. Chow SP, Yau A. Tuberculosis of the knee - A long term followup. Int Orthop 1980;4:87-92.

[39]. Kerri O, Martini M. Tuberculosis of the knee. Int Orthop 1985; 9:153-157

[40]. Leigh Moore S, Rafii M. Advanced imaging of tuberculosis arthritis. Semin Musculoskelet Radiol. 2003;7:143-153.

[41]. Suh JS, Lee JD, Cho JH, et al. MR imaging of tuberculous arthritis: clinical and experimental studies. J Magn Reson Imaging. 1996;6:185-189

[42]. Tuli SM. Tuberculosis of the skeletal system: bones, joints, spine and bursal sheaths. 3rd edition, Bangalore, Jaypee Brothers, 2004.

[43]. Gibson MS, Puckett ML, Shelly ME. Renal tuberculosis. RadioGraphics 2004;24:251-256

[44]. Kenney PJ. Imaging of chronic renal infections. Am J Roentgenol 1990; 155:485-94. Clinical urography, 2nd ed. Philadelphia, PA: Saunders, 2000:1193-1228

[45]. Birnbaum BA, Friedman JP, Lubat E, Megibow AJ, Bosniak MA. Extrarenal genitourinary tuberculosis: CT appearance of calcified pipe-stem ureter and seminal vesicle abscess. J Comput Assist Tomogr 1990;14:653-655

[46]. Baumgarten DA, Baumgartner BR. Imaging and radiologic management of upper urinary tract infections. Urol Clin North Am $1997 ; 24: 545-69$.

[47]. Sawczuk IS, Reitelman C, Libby C, et al. CT findings in Addison's disease caused by tuberculosis. Urol Radiol 1986; 8:44-45.

[48]. Taillefer R, Lemieux RJ, Picard D, et al. Gallium-67 imaging in pericarditis secondary to tuberculosis and histoplasmosis. Clin Nucl Med 1981; 6:413-415.

[49]. Lee G, Im JG, Kim JS, et al. Tuberculosis of the ribs: CT appearance. J Comput Assist Tomogr 1993; 17:363-366.

[50]. Moon WK, Han MH, Chang KH, et al. CT and MR imaging of head and neck tuberculosis. RadioGraphics 1997; 17:391-402. 